Selected Papers from the 9th Radiocarbon \& Archaeology Symposium, Athens, GA, USA, 20-24 May 2019 (C) 2020 by the Arizona Board of Regents on behalf of the University of Arizona. This is an Open Access article, distributed under the terms of the Creative Commons Attribution licence (http://creativecommons. org/licenses/by/4.0/), which permits unrestricted re-use, distribution, and reproduction in any medium, provided the original work is properly cited.

\title{
RESOLVING TIME AMONG NON-STRATIFIED SHORT-DURATION CONTEXTS ON A RADIOCARBON PLATEAU: POSSIBILITIES AND CHALLENGES FROM THE AD 1480-1630 EXAMPLE AND NORTHEASTERN NORTH AMERICA
}

\author{
Sturt W Manning ${ }^{1 *}$ (D) Jennifer Birch ${ }^{2} \cdot$ Megan Anne Conger $^{2} \cdot$ Samantha Sanft $^{3}$ \\ ${ }^{1}$ Cornell Tree Ring Laboratory, Department of Classics and Cornell Institute of Archaeology and Material Studies, \\ Cornell University, Ithaca, NY 14853, USA \\ ${ }^{2}$ Department of Anthropology, University of Georgia, 250 Baldwin Hall, Jackson Street, Athens, GA 30602-1619, \\ USA \\ ${ }^{3}$ Department of Anthropology and Cornell Institute of Archaeology and Material Studies, Cornell University, Ithaca \\ NY 14853, USA
}

\begin{abstract}
Reversals and plateaus in the radiocarbon $\left({ }^{14} \mathrm{C}\right)$ calibration curve lead to similar ${ }^{14} \mathrm{C}$ ages applying to a wide range of calendar dates, creating imprecision, ambiguity, and challenges for archaeological dating. Even with Bayesian chronological modeling, such periods remain a problem when no known order-e.g., a stratigraphic sequence-exists, and especially if site durations are relatively short. Using the reversal/plateau AD 1480-1630 and the archaeology of northeastern North America as our example, we consider possible strategies to improve chronological resolution across such reversal/plateau periods in the absence of stratigraphic sequences, including uses of wood-charcoal TPQs from even very short wiggle-matches, and site phase duration constraints based on ethnohistoric and archaeological evidence.
\end{abstract}

KEYWORDS: Bayesian chronological modeling, Iroquoian archaeology, radiocarbon dating, radiocarbon plateau, wiggle-matching.

\section{INTRODUCTION}

Reversals and plateaus in the radiocarbon $\left({ }^{14} \mathrm{C}\right)$ calibration curve are a recognized challenge for archaeological (and other) dating (Taylor et al. 1996: 661-662). A given set of ${ }^{14} \mathrm{C}$ values contemporary with a plateau produce calendar dating probability spread over a long period, or periods, largely irrespective of the accuracy and precision of the individual ${ }^{14} \mathrm{C}$ measurements. This poses difficulties for resolving succinct and non-ambiguous timeframes for shorter duration contexts, notwithstanding recent efforts to increase ${ }^{14} \mathrm{C}$ definition across some well-known problematic instances of reversals and plateaus in the calibration curve, such as the Hallstatt Plateau ca. 800-400 BC (e.g. Taylor and Southon 2013; Park et al. 2017; Jacobsson et al. 2018). While the Hallstatt Plateau is a well-known problem zone (Hamilton et al. 2015), the reversal and plateau in the radiocarbon record ca. AD 1480-1630 is another conspicuous instance (so-called perturbation Ib in Taylor et al. 1996: table 2, fig. 3A). This latter case has long been held to render radiocarbon dating unable to contribute usefully to high-resolution dating in this recent period, and hence was observed as a key problem for mid second millennium AD North American archaeology (e.g. Pendergast 1993). This is an especial problem since this time period coincides with the emergence of historically documented Indigenous polities, the arrival of the first Europeans to northeastern North America, and the subsequent movement of European objects and later European peoples inland. Considered individually, ${ }^{14} \mathrm{C}$ ages hitting this region of the calibration curve yield wide and often ambiguous (bi-modal) calendar probabilities and date ranges: Figure 1. We note that our paper employs the IntCal13 dataset. The upcoming IntCal20 curve (Reimer et al. 2020) contains greatly increased data density and refinements

*Corresponding author. Email: sm456@cornell.edu. 


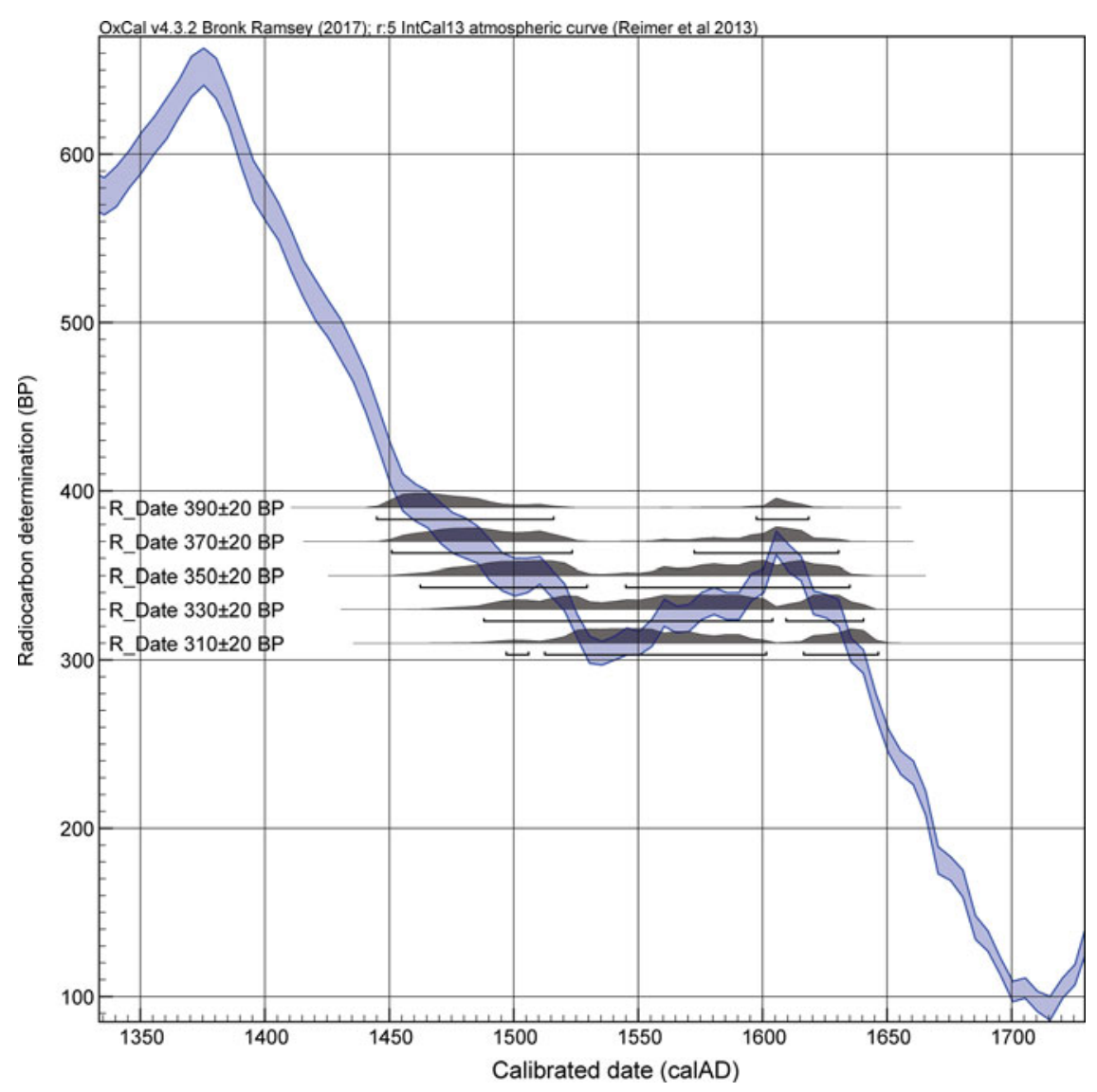

Figure 1 Calendar age calibrated probabilities for five example ${ }^{14} \mathrm{C}$ ages $(390 \pm 20 \mathrm{BP}$ to $310 \pm 20$ $\mathrm{BP})$ lying in the region of the ca. AD $1480-1630$ reversal/plateau in the ${ }^{14} \mathrm{C}$ calibration curve, illustrating how they yield wide, ambiguous, calendar ranges in the region ca. AD 1450-1650. $95.4 \%$ probability ranges are indicated. Data here and in all other figures are from OxCal v.4.3.2 (Bronk Ramsey 2009a) and IntCal13 (Reimer et al. 2013). Curve resolution is set at 5 yr.

from many new annual ${ }^{14} \mathrm{C}$ data in the second millennium AD. The increased fine structure and resolution in the IntCal20 calibration curve will inherently bring improvements, and create some changes in details. Nonetheless, the fundamental issue of calendar resolution across a ${ }^{14} \mathrm{C}$ plateau remains.

Fortunate circumstances excepted, for example, where a set of ${ }^{14} \mathrm{C}$ measurements through the range of values found might indicate the start or end of such a plateau (e.g. Jope 1986), these plateau periods largely resisted resolution before the application of Bayesian chronological modeling. Tree-ring sequenced samples which allow wiggle-match ${ }^{14} \mathrm{C}$ dating (Bronk Ramsey et al. 2001; Galimberti et al. 2004) are the most obvious solution enabling temporal resolution (for a Hallstatt period example, see e.g. Quarta et al. 2010). Although, in situations where only short sequences are available in isolation, these sometimes will potentially remain problematic until calibration curve and sample resolution can be fully aligned (see Bayliss et al. 2017; Jacobsson et al. 2018). In other archaeological cases, where prior stratigraphic or other sequence information are available, the application of Bayesian chronological methods 
has finally allowed varying degrees of chronological resolution to be achieved across such troublesome plateau periods (e.g. Hamilton et al. 2015). This is the classic "archaeological" model, where stratigraphy provides a prior known temporal sequence, and such cases were the basis to the original Bayesian chronological paradigm (Buck et al. 1991, 1992), and popular implementations such as OxCal (Bronk Ramsey 1995).

However, what about cases where a secure multi-element stratigraphic sequence is not available to provide a temporal structure within which sites or phases may be placed for analysis? The Late Woodland Northeast offers such a situation. It is characterized by relatively short one-phase sites with no or very limited vertical stratigraphy. Estimates of relative placements of sites against each other have been proposed, for example based on assessments (and underlying assumptions) from techniques like ceramic seriation, or from various assumptions about timings and distributions of certain material culture types, such as European trade goods (see reviews in Birch and Williamson 2013; Birch 2015; for examples, see MacNeish 1952; Bursey 1993; Fitzgerald et al. 1993, 1995). But all such approaches are assumption-based, rely on untestable stepwise logic transfers, and overall do not offer an independent timeframe. In a few instances, it is believed that community relocation sequences have been identified, where a single community moved from site A to site B to site C (e.g. Birch and Williamson 2013), but even these cases are invariably not without debate or caveat, and again lack an independent basis separate from various inherent assumptions.

Thus, in practical terms, no prior sequential set of time constraints is available independent of archaeological assumptions and guesswork. These circumstances are a challenge for Bayesian chronological modeling. (This is assuming we avoid the circular situation where we merely build a model based on such existing best estimates/assumptions, and hence just aim to demonstrate that this set of prior assumptions is possible-but of course not necessarily correct.) The additional problem of the AD 1480-1630 plateau in the radiocarbon calibration curve then further exacerbates dating ambiguity.

In recent work addressing dating around the AD 1480-1630 period, Manning et al. $(2018 ; 2019)$ employed some available ad hoc solutions to try to help to resolve a timeframe across this plateau and for non-stratified sites and sequences. In the former case, some key elements included: (i) a short dendro-wiggle-match, which usefully constrained the date of one site (Warminster) (Manning et al. 2018: fig. 2); and (ii) selection and dating of terminus post quem (TPQ) dates on charcoal from the early phase of activity at the Jean-Baptiste Lainé (Mantle) site, which constrained its placement (Manning et al. 2018: fig. S9). In the latter case, some elements of the analysis included: (i) the wiggle-match from the Warminster site (Manning et al. 2019: supplemental fig. 1); and (ii) observation that the dates for each site Phase tended to yield very long possible date ranges-hence we tried employing a range of conservative constraints on the length of time represented by the dates obtained within each site Phase. The justification for a constraint is because the Iroquoian sites under investigation are regarded, both from ethnohistoric, and archaeological, evidence (and derived calculations) to be short. A review of scholarship suggests likely maximum durations of $<40 \mathrm{yr}$, and there is a general view in scholarship that larger sites of this period were typically occupied for 20 or $30 \mathrm{yr}$ at most (Warrick 1988; Birch and Williamson 2013; Birch 2015; see also discussion below). Of course, all such rules will inevitably have exceptions. Thus, we considered conservative duration constraints for the Span of the modeled ${ }^{14} \mathrm{C}$ data ranging from a little larger than the expected maximum duration $(50 \mathrm{yr})$ to $3 \times$ the expected maximum duration $(120 \mathrm{yr})$. In Manning and Hart (2019), use of an Interval constraint was substituted to limit overall site 
Phase duration (versus just dated events) within the estimated site Phase Boundaries according to conservative assessments.

Ad hoc strategies of these kinds inherently have strengths and weaknesses, and invariably fail to cover all issues. For example, if the context for which a date is sought happens to lie towards the end of a plateau in the radiocarbon calibration curve, then dating material from the context with in-built age_-like wood charcoal — can successfully offer a key constraint by ruling out the earlier part of the plateau. The Warminster or Jean-Baptiste Lainé (Mantle) cases in Manning et al. (2018) offer examples of this (and another hypothetical example is discussed below). However, if the context of interest lies around the beginning of a plateau, then this same strategy is unlikely to work as effectively. Indeed, it is likely that the effect of creating a TPQ may well be to push the modeled date for the context of interest later along the plateau after accommodating the TPQ information, and so lead to an entirely incorrect age estimate. The only ways to prevent this are either to have a subsequent terminus ante quem (TAQ) constraint (an inherently challenging problem if a sequence of contexts is not known and available), or some means to tie the context to the earlier part of the plateau. One solution here, for example, is potentially using the temporal placement of the in-built age period of a wood-charcoal sample as an additional constraint.

Another issue not addressed in this previous work is whether the assumption of uniform probability for the site Phases is most appropriate, and especially where applying a duration constraint. To explain: if the ethnohistoric information and archaeological assessment is that site Phases were typically no more than $20-30 \mathrm{yr}$, and definitely less than $\sim 40 \mathrm{yr}$ (see above, and further below), then we have a probability estimate that is not uniform. Rather, there is most likelihood for a duration somewhere up to $\sim 20-30 \mathrm{yr}$ (perhaps typically $\sim 10-25 \mathrm{yr}$ ), and then very little probability from $30+$ and especially $40+$ yr. Thus, rather than simply applying a uniform probability assumption, it would seem as, or more, appropriate to consider alternatives that best capture the prior expert knowledge (or at least to compare such an approach with the uniform probability assumption).

In this paper, we consider the effectiveness of some approaches to chronological resolution, using the ca. AD 1480-1630 plateau and the northeastern North America case study as the example. There is no single solution. Rather, we present a toolkit of some possible strategies that can work in various circumstances, especially when paired together, noting caveats and complications. We emphasize the up-to-now underexploited relevance of even short wiggle-matches on wood charcoal samples.

\section{METHODS}

The modeling in this paper employs OxCal 4.3.2 of 2017 (Bronk Ramsey 1995, 2009a, 2009b, 2017; Bronk Ramsey et al. 2001) and the IntCal13 calibration dataset (Reimer et al. 2013), current at the time of writing. We use the current default calibration curve resolution of $5 \mathrm{yr}$. The focus is on practical methods, possibilities, and problems; all cases are hypothetical. We consider two applications of a wiggle-match paired with a duration constraint, and the effects and effectiveness of a duration constraint by itself for plateau cases. For the site Phase duration constraints, we consider both a uniform probability prior (as in previous work), and also some alternatives trying to better capture prior expert knowledge. Example OxCal runfiles for the models shown are provided in the Appendix. OxCal code is listed in Courier format. 
A

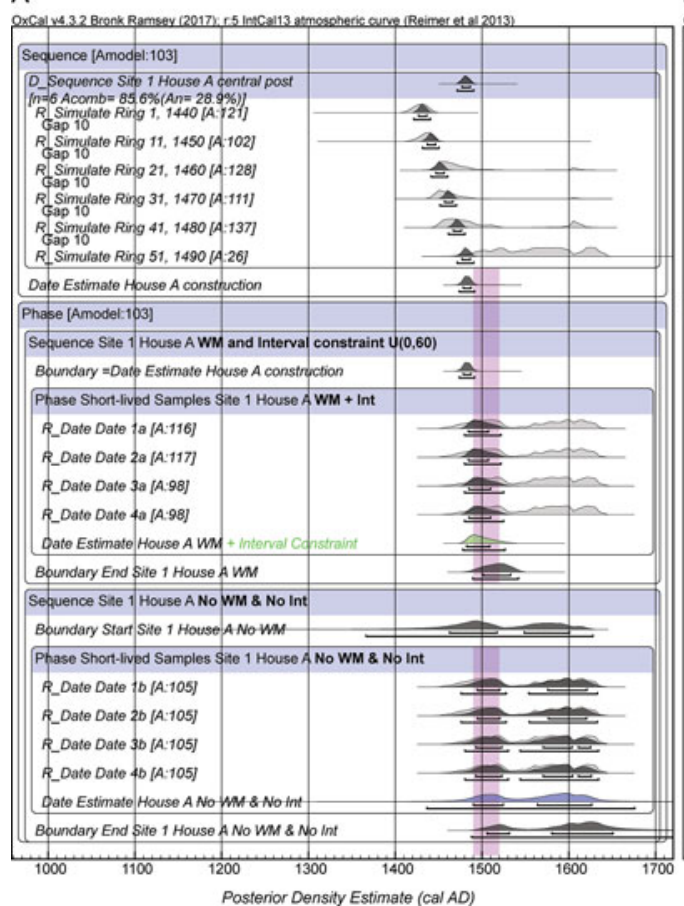

B

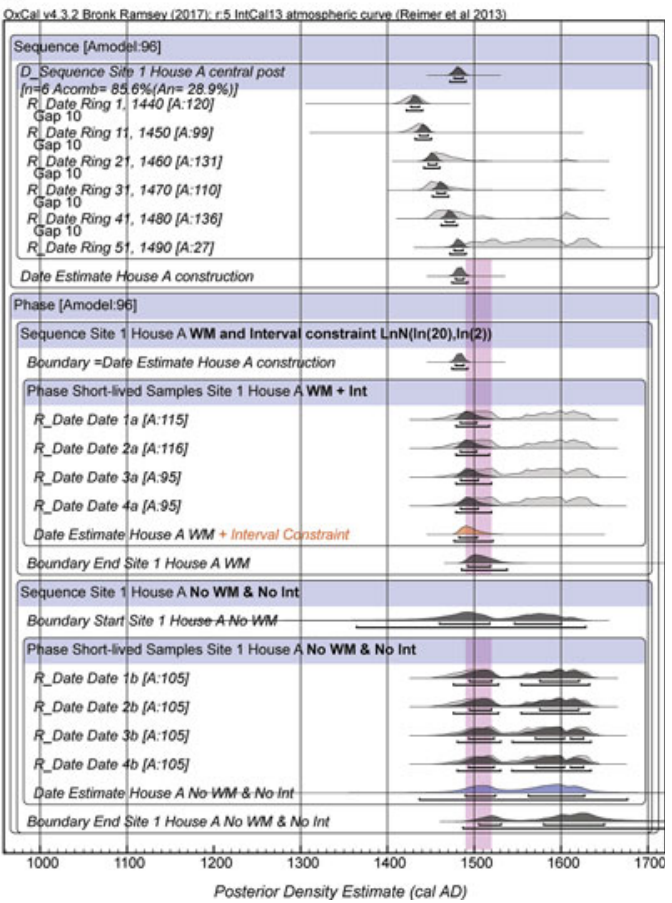

Figure 2 Hypothetical model for Site 1 and House A dated AD $1490-1520$. Four ${ }^{14} \mathrm{C}$ dates on short-lived samples from the site Phase are available (note: the ${ }^{14} \mathrm{C}$ age and error of date $1 \mathrm{a}=$ date $1 \mathrm{~b}, 2 \mathrm{a}=2 \mathrm{~b}$, etc.). The difference is illustrated between the upper version (WM and Interval constraint), which incorporates a wiggle-match on 51-yr post sequence to outermost (waney edge) ring and includes an Interval (Int) constraint versus the lower version (No WM and No Int), which has no such extra constraints. Contrast the respective green or orange versus blue Date estimates. The light magenta bar indicates the correct site age. A. employs a uniform prior of $0-60 \mathrm{yr}, \mathrm{U}(0,60)$ for the constraint on an Interval query for the Phase duration. B. is as A. but instead employs the prior on the Interval query of $\operatorname{LnN}(\ln (20), \ln (2))$.

OxCal key words (like Phase, Boundary, etc.) are capitalized throughout the text. We only report results from successful model runs with $A_{\text {model }}$ and $A_{\text {overall }}$ both $\geq 60$ and Convergence $\geq 95$.

The wiggle-match examples employ the D_Sequence function in OxCal with the periods of time between dated tree-rings stated with the Gap ( ) ; command. The constituent ${ }^{14} \mathrm{C}$ dates for the hypothetical models are sometimes specified; otherwise, they are simulated for a given calendar age using the R Simulate function, or simulated for a randomly generated calendar age anywhere within a site Phase range. The latter employs OxCal code along the lines of: R_Simulate("Date 1", 1480+rand ()*30,20); as an example for a simulated date for a hypothetical short-lived sample from a site dating AD 1480-1510 with a ${ }^{14} \mathrm{C}$ dating error of \pm 20 . If a period of time is estimated beyond the last extant tree-ring, and before use in human construction (e.g. $1 \pm 1$ yr covering instances of cutting in the fall, allowing drying over winter, and then use the following spring/summer, versus immediate use), then this is modeled using the Interval(); command, e.g.: Interval ("Use Timber", $N(1,1)$ ); (see the models in Figure 2). The main proposed additional constraint tested in the examples is the addition of a duration constraint. The first case is where a date or TPQ from the last event in a D_Sequence defines the start of a site Phase, and we then wish to constrain the maximum duration from that point to the end of 
this Phase. The second case is where the date for an outermost tree-ring in a short D_Sequence belongs within a site Phase, and we wish at the same time to constrain the maximum period of time (duration) of the Phase.

The first case, employed in the model in Figure 2A, uses the Interval ( ) ; command, and a uniform probability assumption, and merely sets the duration constraint as, arbitrarily, $2 \times$ the maximum estimated site Phase length, thus Interval ("Duration", $U(0,60)$ ) ; where a maximum of a $30-y r$ site phase is considered reasonable. The site Phase itself is dated by randomly simulated dates on four short-lived samples from the site period. Such maximum site durations, while based on ethnohistoric observations and archaeological criteria (post densities, site catchment exhaustion estimates, and so on), are of course themselves estimates. Thus, we assume sensible analysis will consider a range of possible duration constraints to determine when and whether there is a change in outcomes, and then to discuss a choice within such a range for a particular case. We note we employ Interval and not Span. Interval quantifies the period of time between the start and end Boundaries of a Phase-what such total site duration estimates refer to-whereas Span quantifies only the period of time represented by the specific ${ }^{14} \mathrm{C}$ dates in the dated set. Hence, unless a large and truly comprehensive set of dates, the latter will inevitably not reflect the total duration of the Phase of interest, whereas the former is trying to estimate the target period of interest.

However, as noted above, the prior assumption of a uniform distribution for the duration in fact appears less than ideal. If we have expert knowledge that the duration should be no more than $30 \mathrm{yr}$, then allowing a 50\% probability for a range greater than this undervalues this prior information. The arbitrary option would be to reduce the uniform prior; for example to $0-45$ $\mathrm{yr}$, regarding $40 \mathrm{yr}$ as the total maximum and allowing for only a possible small error on this assumption. However, better, we might instead consider a prior that gives greater weight to the expected range and then much less weight to a range beyond this. One option would be a Normal distribution, e.g. Interval ("Duration", N (20,10)); (see Figure 3C), but probably more appropriate is a $\mathrm{LnN}$ distribution, e.g. Interval("Duration", $\operatorname{LnN}(\ln (20), \ln (2)))$; since this does not limit the upper range if, in fact, the data do turn out to indicate a longer site duration than expected. The complication in all this is of course the calibration curve. If a site dates e.g. $\sim 1500$ then it can also date around $100 \mathrm{yr}$ later in the early 17 th century-which is impossible if total site duration is short. Nonetheless, depending on the dataset, some runs of models will inevitably try to use such a late fit, even if it is unlikely. The control over this comes from using only model results with (i) $\mathrm{A}_{\text {model }}$ and $\mathrm{A}_{\text {overall }}$ values $\geq 60$ and (ii) acceptable OxCal Convergence (C) values $\geq 95$ for all elements. In cases of problematic model runs, one or both of these requirements will usually not be achieved.

Figure $2 \mathrm{~B}$ reruns the model in Figure 2A using the LnN Interval constraint. Of course, the exact choice, e.g. $\ln (15)$ or $\ln (20)$ or $\ln (25)$, etc., and error, e.g. $\ln (1)$ or $\ln (2)$ or $\ln (3)$, etc., is arbitrary. The aim is to anticipate a rapid rise in possible probability from $0 \mathrm{yr}$ to a most likely expected duration around $\sim 10-25 \mathrm{yr}$ (the estimated modal site duration), with probability then declining rapidly afterwards, but with no actual hard upper limit. The choice of Interval("Duration", $\operatorname{LnN}(\ln (20), \ln (2)))$; offers a probability distribution which is similar to the available expert knowledge for the Iroquoian case (Figure 3B). Clearly, if a specific site is believed to have a shorter, or longer, duration for various reasons, then this Interval model should be adjusted. In Figure 3 we compare the use of an Interval constraint with each of the priors mentioned above, $\mathrm{U}(0,60)$ (Figure $3 \mathrm{~A}$ ), 

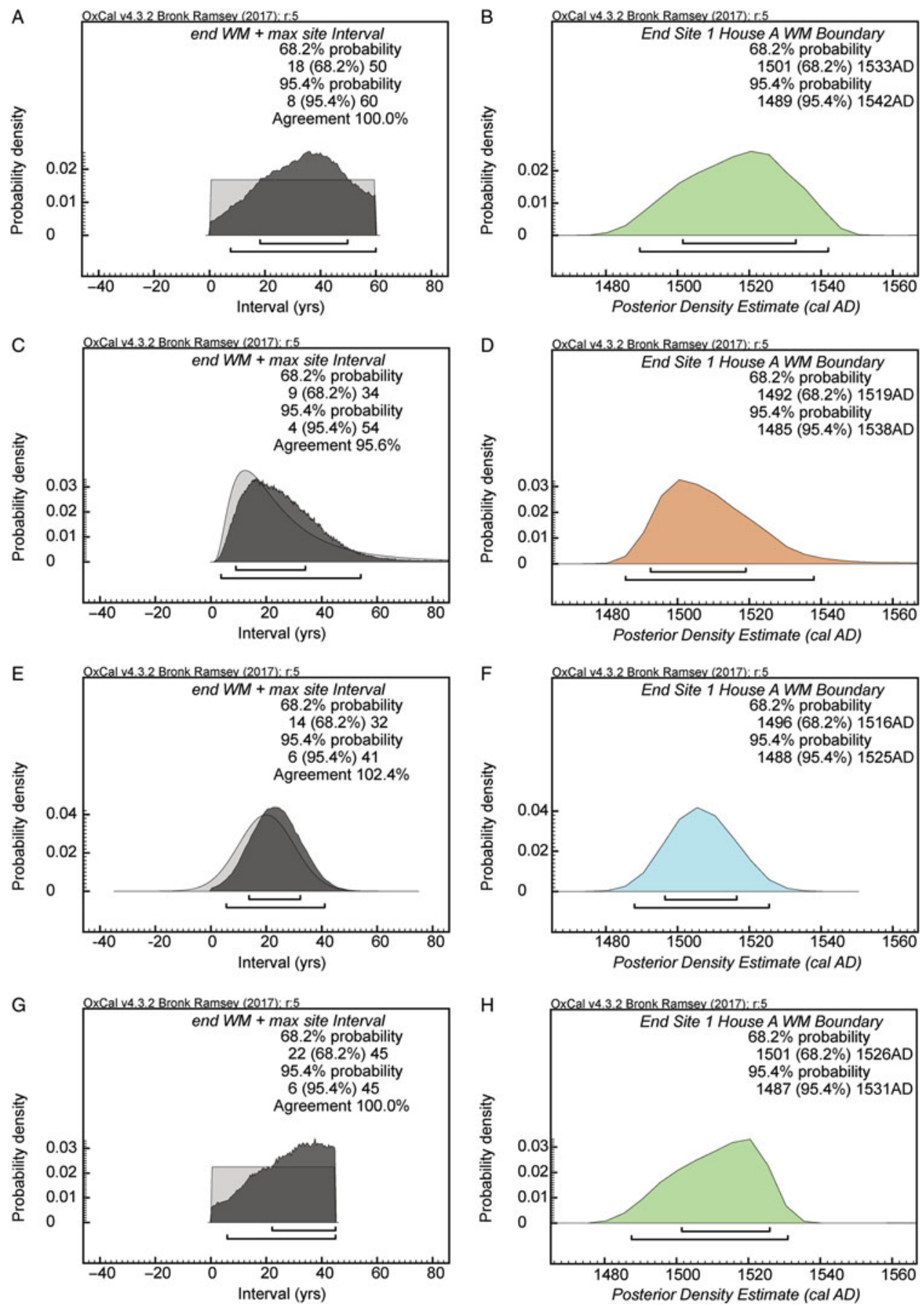

Figure 3 Comparison of the results for runs of the Figure 2 model comparing: (i) the duration of time (the site Phase) from the end of the Wiggle-Match to the end of the Phase (end WM + max site Interval), and (ii) the dating probabilities for the end of site Phase Boundary (End Site 1 House A WM Boundary), for versions of the model (same ${ }^{14} \mathrm{C}$ values as in Figure $2 \mathrm{~A}$ ) employing different priors for the Interval query constraint as discussed in the text. A and B employ the prior $\mathrm{U}(0,60), \mathrm{C}$ and $\mathrm{D}$ employ $\operatorname{LnN}(\ln (20), \ln (2)), \mathrm{E}$ and $\mathrm{F}$ employ $\mathrm{N}(20,10)$ and $\mathrm{G}$ and $\mathrm{H}$ employ $\mathrm{U}(0,45)$. 
A

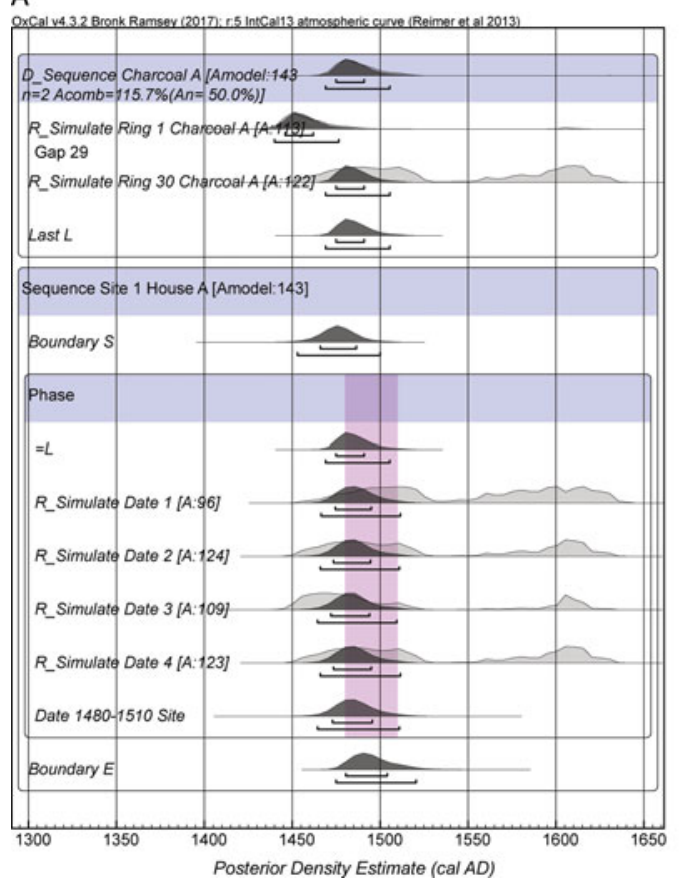

B

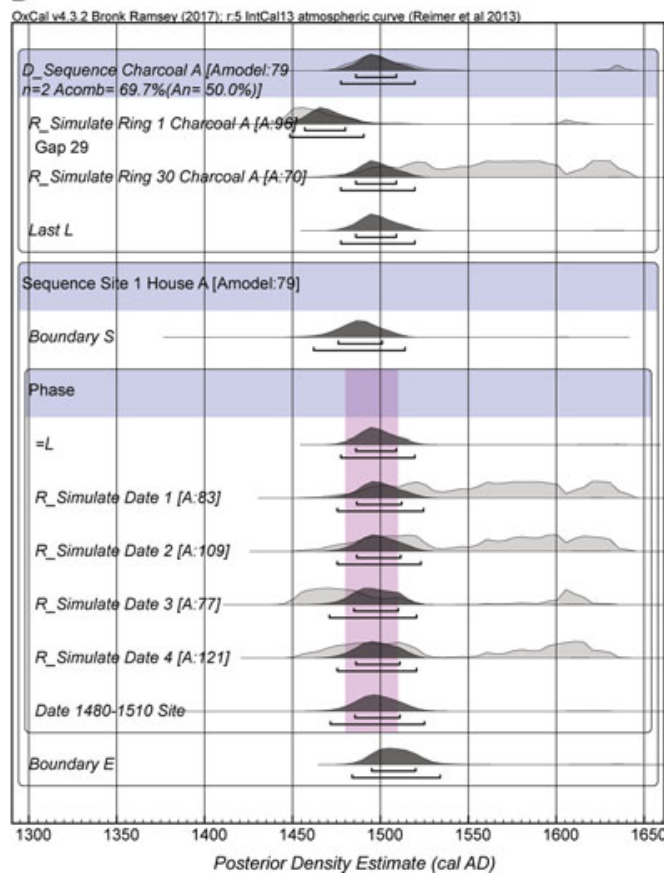

Figure 4 A. Example run of a model where a 30-yr charcoal sample comes from year 1 of a site Phase (e.g. construction). B. Example run where a 30-yr charcoal comes from year 15 of the site Phase (so renewal, expansion, etc.). A duration constraint prior of $\operatorname{LnN}(\ln (20), \ln (2))$ is applied to an Interval query between Boundary S to Boundary E (see text). The site Phase dates AD 1480-1510; light magenta bar indicates the site Phase date range. $68.2 \%$ and $95.4 \%$ hpd ranges are indicated.

$\operatorname{LnN}(\ln (20), \ln (2))$ (Figure 3C), N(20,10) (Figure 3E) and U(0,45) (Figure 3G), for the same case (using the same ${ }^{14} \mathrm{C}$ ages found by the $\mathrm{R}_{-}$Simulate function in the Figure $2 \mathrm{~A}$ model run).

For the second case we use both the increased resolution available from a Wiggle Match placement, even from a short tree-ring sequence, paired with a duration constraint applied via a constraint on an Interval query. We consider the following example case. There is a 30-tree-ring (i.e. years) small roundwood charcoal sample from a hypothetical site Phase dating AD 1480-1510. Ideally, this sample has evidence of bark or waney edge. Bark or waney edge are not uncommon on such samples, and, where present, the outermost ring defines human use of the sample. However, even when bark or waney edge is not recognized or present, there are still likely very few missing rings for such small roundwood samples, and so we can still regard the outermost ring as approximately defining a date within the site Phase. Either way, we can assume that ring 30 (the outermost ring) defines a point within the site Phase. This date ("L" in Figure 4) is better defined in contrast to a single ${ }^{14} \mathrm{C}$ date because of the wiggle-match since the dates on ring 1 and ring 30 must be 29 rings (= years) apart. In addition, we can assume, based on expert knowledge, the same maximum of $\sim 30-40$ yr duration for such a site Phase as considered in the Figure 2 and 3 models. Therefore, we can model and constrain the expected overall duration of the site Phase between the start Boundary (S) and the end Boundary (E) by, for example, an Interval query using the prior of $\operatorname{LnN}(\ln (20), \ln (2))$, as discussed above. A slightly different alternative would be to use the OxCal Difference 
command and the code: Difference ("D", "E", "S", LnN ( $\ln (20), \ln (2)))$; We try two different scenarios to illustrate the range of potential cases. In the first, the charcoal sample is assumed from use (e.g. construction) in year 1 of the site (AD 1480), and, in the second, the charcoal is assumed to relate to use in year 15 of the site (renewal, expansion, in the middle of the site's overall life-cycle). For the site Phase we have four random ${ }^{14} \mathrm{C}$ dates on short-lived samples from the Phase. In case it is felt that the choice of the $\mathrm{LnN}$ prior is decisive, we also consider a simple uniform prior of $0-50 \mathrm{yr}$, which more than covers the assumed maximum site duration of $<30-40 \mathrm{yr}$ (see below), and even some error.

The basis to the maximum site duration estimates in each of these cases is a body of scholarship reviewing ethnohistoric information, and archaeological observations and calculations concerning site sustainability criteria, for sites in northeastern North America in the 15th to 17 th centuries AD. As briefly noted above, this suggests that for any of the substantial and larger settlements the total site durations were only of a few decades at most. An average figure around or less than 15-20 yr is the norm (Thwaites 1896-1901, 10:275, 15:153; Biggar 1922-1936, 3:124; Wrong 1939:92; Sykes 1980; Fitzgerald 1986:120), and a plausible maximum duration of about 30 yr (Fitzgerald et al. 1995:127-131), or 40 yr (Warrick 1988) is evident. Snow (1995: 135) made a theoretical sustainability argument for some small sites potentially having longer durations. However, even so, no scholar (including Snow 1995) has regarded any such sites having total durations beyond ca. 50-75 yr (see also Timmins 1997 and his analysis of the small, 0.2 ha, Early Iroquoian Calvert site) —and we are assuming in this hypothetical exercise that we are not working either with such small, or earlier, sites. The figure of $<30-40 \mathrm{yr}$ is a statement of the maximum single duration of a village site. Of course, a site locus could be reused over time, with intervals in-between, allowing local area regeneration and recovery (for example, this reuse model is assumed in some cases for the Mohawk Valley by Snow 1995). Review of all such considerations leaves us with a generally accepted maximum village life-cycle estimate of around 30-40 yr (and the typical duration is considered to be less than this maximum figure, perhaps, as suggested above, with an expected modal range somewhere around 10-25 yr). However, recognizing that such numbers are of course estimates, which describe a range, and that there will always be exceptions, we tried a range of plausible, but conservative, site duration constraints in previous applications (Manning et al. 2019; Manning and Hart 2019), and regard assessing the effects of a range of values as part of any modeling experiment and investigation. In practical terms, if the constraint is made too short, it can be difficult to get a model with several site Phases to run successfully (changing curve resolution to $1 \mathrm{yr}$ assists, but only so far). As noted above, here we consider also alternatives to a uniform probability prior estimate for the site durations.

The final issue we consider is application of a duration constraint by itself on a Phase. A feature noted for site Phases lying on a ${ }^{14} \mathrm{C}$ plateau is that they tend to indicate wide (and ambiguous) possible dating ranges. The question is the effectiveness of trying to constrain such possible site Phase durations. In particular, in Manning et al. (2019) and Manning and Hart (2019), it seemed that this approach could offer some degree of guidance especially for ambiguous sites in the middle period of a plateau - although this was not always clear. To consider the context, we can examine the calibration curve between 1450 and 1650 (Figure 1). If we analyze the 5-yr IntCal13 dataset against itself as a set of independent ${ }^{14} \mathrm{C}$ values placed within a Phase with an Order query applied, there are potential order inversions (because of the reversal in the calibration curve): Figure 5A. The correct calendar temporal order 


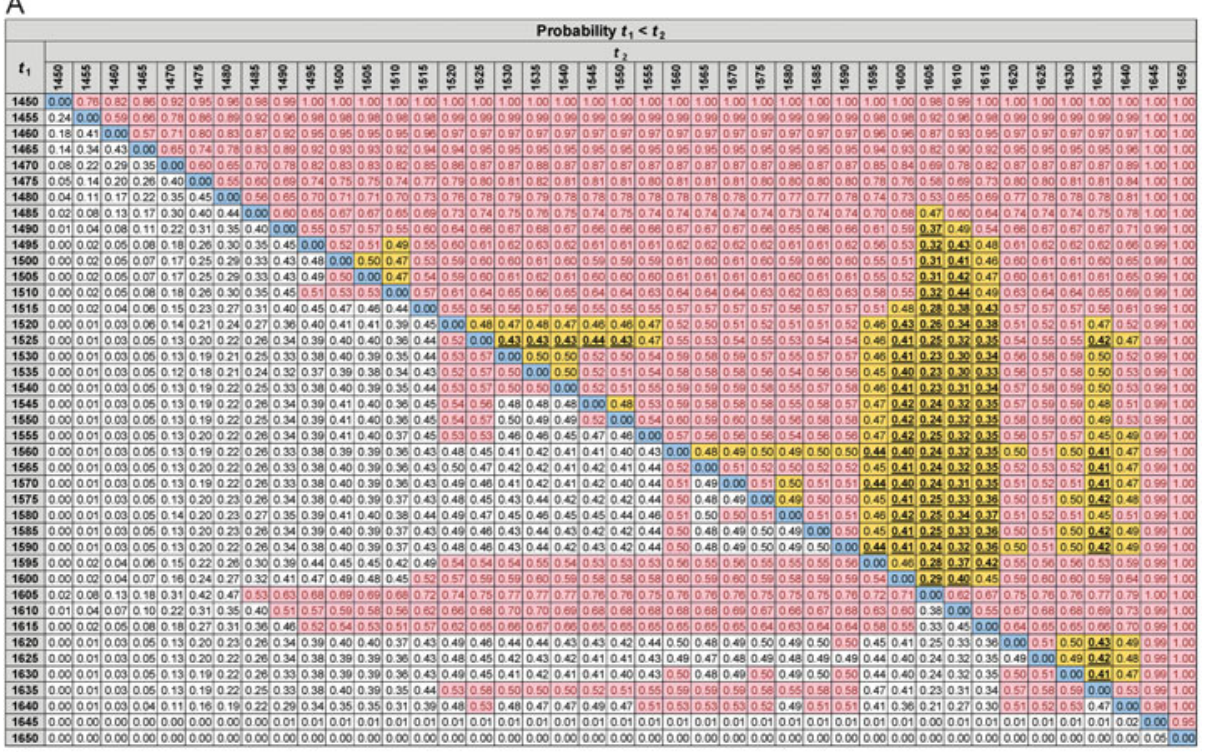

B

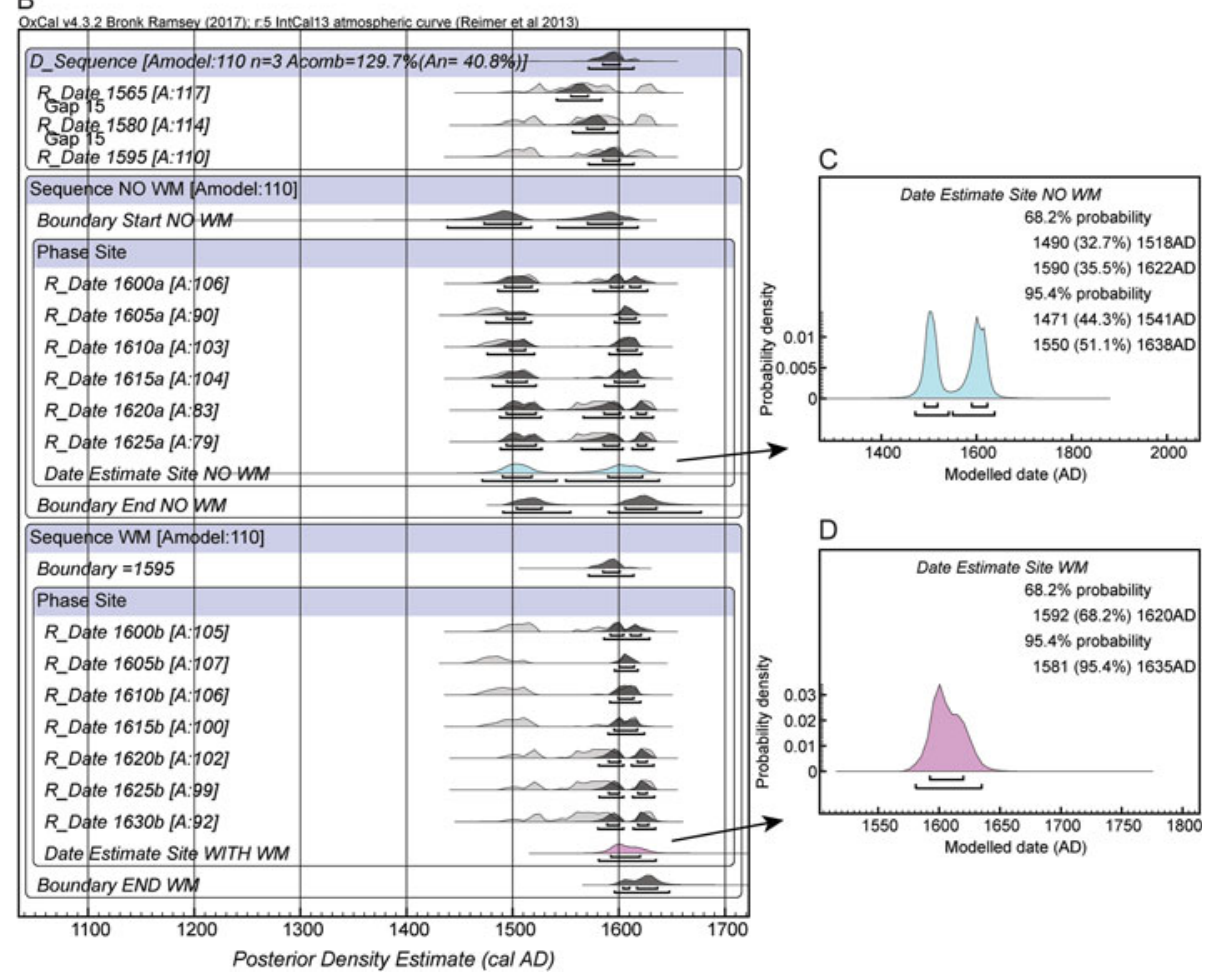

Figure 5 A. Order analysis and probabilities for the ${ }^{14} \mathrm{C}$ ages of the IntCal13 calibration dataset (Reimer et al. 2013) when placed as independent elements within in an overarching Phase. If the chronological order were correct all the cells above the blue line would be red. Instead, as indicated by the yellow cells (and the corresponding red cells below the blue line), due to the reversal in the calibration curve AD 1595-1615, there is a mis-ordering especially as relates to comparisons with the AD 1595-1615 values. B. A hypothetical Site Phase comprising the IntCal13 values for AD $1600-1625$ is considered. Within no additional constraint the Date estimate is entirely ambiguous (cyan histogram) either around AD 1500 or around AD 1600 for 'Date Estimate Site NO WM'. In contrast, including the short 3-date wiggle-match on a 31-yr hypothetical wood-charcoal sample (using the $\mathrm{AD}$ 1565, 1580 and 1595 values from IntCal13) with the last ring setting the start Boundary for the site Phase, then the site Phase Date estimate is closely resolved around the AD 1600 possibility: magenta histogram for 'Date Estimate Site WITH WM'. C. and D. show details of the respective site Date estimates without $(C)$ and then with (D) the inclusion of the wiggle-match. 
should see only red shaded cells above the blue line. But, for a few periods, we see contradictory values (yellow cells). Those values in bold and underlined indicate the wrong calendar order by more than 5\% probability. In particular, the incorrect order occurs when comparing values from $\sim 1490-1600$ against those from the narrow time period of $\sim 1595-1615$. This age inversion is apparent in Figure 1. The simplest solution, where available, is to use a wigglematch, even a short one, either to remove the late early 17 th century possibility (Figure 2 ), or to rule out the 16th century (Figure 5B-D) (and see the Warminster example in Manning et al. 2018). Figure 5B offers another example, employing data direct from IntCal13. With no other constraint, a set of "perfect" dates for a site dating 1600-1625 nonetheless yield a date estimate that is highly ambiguous (Figure 5C). However, incorporation of a wiggle-match element, using 3 dates over a hypothetical 31-yr sample taken from IntCal13, enables close resolution of the correct site age (Figure 5D).

Without an extra constraint, like a wiggle-match, simply constraining the site Phase duration will have limited effect. As evident from Figure 5A, if the constraint is made too short, then the ambiguity remains with multiple possible ranges, e.g., around 1500 or 1600 . If the constraint is too long, then it lacks any real utility. However, in-between, the order information in Figure 5A would suggest that where data comes from a site Phase spread over a period of several decades then, with the clear exception of the period around 1595-1615, one might hope in at least some cases to obtain an indication of the correct order (e.g. for the period from $\sim 1450$ 1600). We consider these circumstances across four instances with data drawn from IntCal13 to consider what a "perfect" case could be. Examples 1 and 2 employ 30-yr site Phases with equal (uniform) distribution of dates across the phases of approximately a. 1448-1477, b. 1478-1507, c. 1508-1537, d. 1538-1567, e. 1568-1597 and f. 1598-1627 (and then the same $+15 \mathrm{yr}$ for example 2) created with the IntCal datapoints between these ages, and we determine the resultant Order information obtained for the site Phases, when placed as independent site Phases of the form:

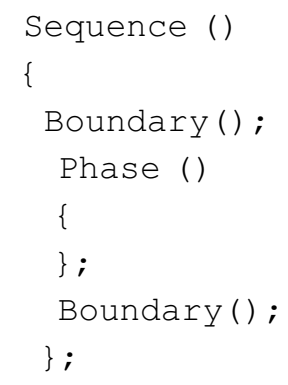

within an over-arching Phase, depending on applying (i) no additional constraint, and then with Interval constraints of (ii) $\mathrm{U}(0,120)$, (iii) $\mathrm{U}(0,80)$, (iv) $\operatorname{LnN}(\ln (20), \ln (2))$ and (v) $\mathrm{N}(15,7.5)$ covering a range from wide/loose to tighter constraints. Examples 3 and 4 follow the same approach but employ 40-yr site Phases of a. 1448-1487, b. 1488-1527, c. 1528-1567, d. 1568-1607 and e. 1608-1647 (and then the same +20 yr for example 4). The Interval constraints in this case are (i) no additional constraint, (ii) $\mathrm{U}(0,120)$, (iii) $\mathrm{U}(0,80)$ (and $\mathrm{U}(0,100$ for example 4, see below), (iv) $\operatorname{LnN}(\ln (20), \ln (2))$ and (v) $\mathrm{N}(20,10)$. In all cases we use and compare the results of an Order (); query applied to the OxCal Date(); queries for each site Phase. The Date query estimates the calendar dates describing the period between the start and end Boundaries for a Phase. It is not a 
measure of duration (the Interval query performs this function), but it is a good description of the approximate calendar date of the modeled Phase.

\section{RESULTS AND DISCUSSION}

\section{Wiggle-Match Samples with Additional Time Constraints}

As noted above, a known time-series appears the obvious route to temporal definition on a reversal or plateau in the ${ }^{14} \mathrm{C}$ calibration curve. Where a context of interest lies towards the end of a plateau, then a wiggle-match can occupy and rule out much of the dating probability from the earlier part of the plateau that would otherwise have created ambiguity (e.g. Manning et al. 2018: fig. 2) (see Figure 5B-D). But what about the situation where the context of interest lies around the early part of the plateau? Figure 2 illustrates a hypothetical example for a site (Site 1) placed about AD 1490-1520 showing the potential difference in dating comparing with wiggle-match (WM) versus without wiggle-match instances. Here we assume a 51-yr tree-ring sample from a central post in House A at Site 1 ending in a likely complete outermost ring (waney edge, ring immediately below bark). We assume use of the timber as a post within $1 \pm 1$ yr of felling. A wiggle-match is run on the post's tree-rings (numbered from ring $1=$ innermost ring) 1, 11, 21, 31, 41 and 51, each spaced $10 \mathrm{yr}$ apart (R_Simulate for AD $1450 \ldots 1490$ employed - thus every run of the model somewhat differs - but note that the same simulated dates from the Figure $2 \mathrm{~A}$ model run are employed in the Figure 2B model and Figure 3 models so that all these models compare the same data). House $\mathrm{A}$ also produced four ${ }^{14} \mathrm{C}$ dates on short-lived samples from its period of use (same ages used in each instance so the site date is controlled, ${ }^{14} \mathrm{C}$ ages $\mathrm{BP}$ of $350 \pm 20$, $350 \pm 20,340 \pm 20,340 \pm 20$ ). As evident in Figures $2 \mathrm{~A}$ and $\mathrm{B}$, No WM, the four House A dates on short-lived samples, with no other constraints, offer a very wide Date estimate for the context (Blue histograms) of (overall) cal AD 1490-1625 (68.2\%) or 1435-1675 (95.4\%) (note: all highest posterior density, hpd, estimates are quoted in the text as rounded outwards to 5 -yr increments). Even if we apply a constraint to the maximum duration of the site, for example using the $\operatorname{LnN}(\ln (20), \ln (2))$ model above, then this alone only reduces the hpd ranges a little by removing the extremities of the above ranges (to cal $\mathrm{AD} 1495-1515,27.4 \%$, and $1575-1625,40.8 \%$ at $68.2 \% \mathrm{hpd}$, and $1480-1525,38.3 \%$ and $1555-1635,57.1 \%$ at $95.4 \%$ hpd). Thus useful, but not a route to the correct specific age of about AD 1490-1520.

In contrast, with the wiggle-match and the site duration limits, we have two key constraints to apply. The wiggle-match constrains the start date (TPQ) for House A, and, since we know these sites are of short duration, we may assume a maximum period of time is possible for the House/ Site context after the construction episode. We consider use of the uniform 0 to $60 \mathrm{yr}$ constraint and also the $\operatorname{LnN}(\ln (20), \ln (2))$ constraint on an Interval query - only this time there is a starting point, given the wiggle-match. As evident in Figures $2 \mathrm{~A}$ and $\mathrm{B}$, the change in dating resolution is substantial. Now House A (in the example runs shown) dates (Figure 2A) 1505-1535 (68.2\%) and $1485-1545(95.4 \%)$ and (Figure 2B) $1490-1515(68.2 \%)$ and $1485-1535(95.4 \%)$. It is important to emphasize in a case like this, where the possible ambiguity is to more recent ages, that the wiggle-match alone could not resolve the dating; it was the combination with the Interval constraint that created resolution. Thus the same model with no Interval constraint applied, and only the wiggle-match, usually produces a Date estimate for Site 1/ House A only partly improved from the one with no wiggle-match (example run: 1485$1520,68.2 \%$, but $1480-1620,95.4 \%$ ) since in this case the substantial region of ambiguity is mainly to the recent side. For a context in the middle of a plateau on the calibration curve, 
the duration constraint will also be key; wiggle-match constraining earlier ambiguity, and the duration helping to constrain later ambiguity.

The choice of the prior for the Interval constraint is an important point as noted above. Figure 3 compares the results for the modeled Phase Interval duration and the date for the end Boundary (from the Figure 2 models) considering four different instances all using the same data (from Figure 2A). Figures $3 \mathrm{~A}$ and $\mathrm{B}$ show results from a uniform prior of 0-60 yr U(0,60) (as Figure 2A), C and D show the $\operatorname{LnN}(\ln (20), \ln (2))$ prior (as Figure 2B), E and $\mathrm{F}$ show a normal prior of $\mathrm{N}(20,10)$, and $\mathrm{G}$ and $\mathrm{H}$ show a shorter uniform prior of $0-45 \mathrm{yr}$ $\mathrm{U}(0,45)$. All the results in this case are broadly similar; with slightly wider calendar ranges for the less precise $\mathrm{U}(0,60)$ prior, and more precise ranges in the other cases. Different starting data will lead to variations in results (versus those shown in Figure 3). However, the examples shown here indicate that although consideration of different priors and selection of an appropriate choice is important, in fact, given efforts in each case to describe approximately similar and short constraint periods, the various options for a prior make only relatively modest end differences.

To explore and illustrate this issue further with a real example, we reconsider Manning and Hart (2019) Model 2. The site Phase durations involved in this case are considered broadly to be of a similar range to the instances discussed above, but some might have been a little longer (Snow 1995) and the available ${ }^{14} \mathrm{C}$ dates for certain of the sites could indicate likely site durations potentially longer than a 30-40 yr maximum (Manning and Hart 2019: Table 3). The data sets involved, which include legacy dates from several laboratories and different sample types, in addition to a set of recent AMS ${ }^{14} \mathrm{C}$ results, further include some complicating additional noise. As a result, use of the relatively tight prior of $\operatorname{LnN}(\ln (20)$, $\ln (2)$ ), as above, does not achieve satisfactory $\mathrm{A}_{\text {model }}$ and $\mathrm{A}_{\text {overall }}$ values (typically $\mathrm{A}_{\text {model }}=$ $\sim 41$ and $\mathrm{A}_{\text {overall }}=\sim 50$ ). (Similar issues apply to choices such as $\operatorname{LnN}(\ln (20), \ln (3)$ ) or $\mathrm{LnN}(\ln (20), \ln (4))$ or $\operatorname{LnN}(\ln (25), \ln (3))$.) Some sites with indications of a spread of dates within their site set, in particular Getman and Otstungo, yield poor OxCal Agreement values for the Interval, and often do not achieve satisfactory Convergence values. We thus instead employ a prior that is looser to reflect and accommodate the data: $\operatorname{LnN}(\ln (30)$, $\ln (3))$. This can achieve satisfactory $\mathrm{A}_{\text {model }}(\sim 65)$ and $\mathrm{A}_{\text {overall }}(\sim 73)$ values with all Convergence values $\geq 95$. If we compare the resultant Order probabilities from this model run with the results from the uniform prior models in Manning and Hart (2019: Table 4), we find, despite the different priors, very similar results. Figure 6 gives an example, comparing the $\operatorname{LnN}(\ln (30)$, $\ln (3)$ ) model with the $0-120$ yr uniform prior example in Manning and Hart (2019: Table 4). As would be expected, we observe small differences (and these vary between runs of each model), but the pattern is very similar. The potential ambiguity between Cayadutta and Garoga (evident in the $\operatorname{LnN}(\ln (30), \ln (3))$ model) was noted in Manning and Hart (2019), and especially as the constraint interval was shortened (Manning and Hart 2019: Table 4).

To the majority of readers, the concept of the "wiggle-match" probably implies longer multidecadal, even centennial tree-ring samples. Usually good precision is the aim (unless the method is employed simply as a range-finder for dendrochronology: e.g. Pearl et al. 2020). However, valuable information can still be extracted from short sequences (e.g. Bayliss and Tyers 2004; Bayliss et al. 2017; Galimberti et al. 2004; Hogg et al. 2017), and even with just two or a very few dates (of course, the more dates the more accurate and precise the wigglematch: Galimberti et al. 2004). Where the outermost preserved tree-ring is associated with 
A

\begin{tabular}{|c|c|c|c|c|c|c|c|c|c|c|c|}
\hline \multirow[b]{2}{*}{$t_{1}$} & \multicolumn{3}{|c|}{$\operatorname{Ln}((\ln (30),(3))$} & \multicolumn{3}{|c|}{ Probability $t_{1}<t_{2}$} & \multicolumn{5}{|c|}{$A_{\text {model }}=\sim 65, A_{\text {overall }}=\sim 73$} \\
\hline & $\begin{array}{l}\text { Date } \\
\text { Snell }\end{array}$ & $\begin{array}{c}\text { Date } \\
\text { Pethick }\end{array}$ & \begin{tabular}{c|} 
Date \\
Second \\
Woods
\end{tabular} & $\begin{array}{c}\text { Date } \\
\text { Getman }\end{array}$ & $\begin{array}{l}\text { Date } \\
\text { Elwood }\end{array}$ & $\begin{array}{c}\text { Date } \\
\text { Smith- } \\
\text { Pagerie }\end{array}$ & $\begin{array}{c}\text { Date } \\
\text { Otstungo }\end{array}$ & $\begin{array}{l}\text { Date } \\
\text { Klock }\end{array}$ & $\begin{array}{c}\text { Date } \\
\text { Cayadutta }\end{array}$ & $\begin{array}{c}\text { Date } \\
\text { Garoga }\end{array}$ & $\begin{array}{c}\text { Date } \\
\text { Wormuth }\end{array}$ \\
\hline Date Snell & 0.00 & 1.00 & 1.00 & 1.00 & 1.00 & 1.00 & 1.00 & 1.00 & 1.00 & 1.00 & 1.00 \\
\hline Date Pethick & 0.00 & 0.00 & 1.00 & 1.00 & 1.00 & 1.00 & 1.00 & 1.00 & 1.00 & 1.00 & 1.00 \\
\hline $\begin{array}{l}\text { Date Second } \\
\text { Woods }\end{array}$ & 0.00 & 0.00 & 0.00 & 0.55 & 0.71 & 0.95 & 0.93 & 0.99 & 0.98 & 0.99 & 0.98 \\
\hline Date Getman & 0.00 & 0.00 & 0.45 & 0.00 & 0.58 & 0.82 & 0.86 & 0.93 & 0.93 & 0.97 & 0.95 \\
\hline Date Elwood & 0.00 & 0.00 & 0.29 & 0.42 & 0.00 & 0.85 & 0.86 & 0.94 & 0.93 & 0.96 & 0.94 \\
\hline $\begin{array}{l}\text { Date Smith- } \\
\text { Pagerie }\end{array}$ & 0.00 & 0.00 & 0.05 & 0.18 & 0.15 & 0.00 & 0.61 & 0.72 & 0.74 & 0.80 & 0.77 \\
\hline $\begin{array}{c}\text { Date } \\
\text { Otstungo }\end{array}$ & 0.00 & 0.00 & 0.07 & 0.14 & 0.14 & 0.39 & 0.00 & 0.55 & 0.62 & 0.66 & 0.68 \\
\hline Date Klock & 0.00 & 0.00 & 0.01 & 0.07 & 0.06 & 0.28 & 0.45 & 0.00 & 0.59 & 0.65 & 0.66 \\
\hline $\begin{array}{c}\text { Date } \\
\text { Cayadutta }\end{array}$ & 0.00 & 0.00 & 0.02 & 0.07 & 0.07 & 0.26 & 0.38 & 0.41 & 0.00 & 0.50 & 0.56 \\
\hline Date Garoga & 0.00 & 0.00 & 0.01 & 0.03 & 0.04 & 0.20 & 0.34 & 0.35 & 0.50 & 0.00 & 0.60 \\
\hline $\begin{array}{c}\text { Date } \\
\text { Wormuth }\end{array}$ & 0.00 & 0.00 & 0.02 & 0.05 & 0.06 & 0.23 & 0.32 & 0.34 & 0.44 & 0.40 & 0.00 \\
\hline
\end{tabular}

B

\begin{tabular}{|c|c|c|c|c|c|c|c|c|c|c|c|}
\hline \multirow[b]{2}{*}{$t_{1}$} & \multicolumn{3}{|c|}{$U(0,120)$} & \multicolumn{2}{|c|}{ Probability $t_{1}<t_{2}$} & \multicolumn{3}{|c|}{$\mathrm{A}_{\text {model }}=\sim 91, \mathrm{~A}_{\text {overall }}=\sim 84$} & \multirow[b]{2}{*}{$\begin{array}{c}\text { Date } \\
\text { Cayadutta }\end{array}$} & \multirow[b]{2}{*}{$\begin{array}{c}\text { Date } \\
\text { Garoga }\end{array}$} & \multirow[b]{2}{*}{$\begin{array}{c}\text { Date } \\
\text { Wormuth }\end{array}$} \\
\hline & $\begin{array}{l}\text { Date } \\
\text { Snell }\end{array}$ & $\begin{array}{l}\text { Date } \\
\text { Pethick }\end{array}$ & $\begin{array}{l}\text { Date } \\
\text { Second } \\
\text { Woods }\end{array}$ & $\begin{array}{l}\text { Date } \\
\text { Getman }\end{array}$ & $\begin{array}{l}\text { Date } \\
\text { Elwood }\end{array}$ & $\begin{array}{c}\text { Date } \\
\text { Smith- } \\
\text { Pagerie }\end{array}$ & $\begin{array}{c}\text { Date } \\
\text { Otstungo }\end{array}$ & $\begin{array}{l}\text { Date } \\
\text { Klock }\end{array}$ & & & \\
\hline Date Snell & 0.00 & 0.99 & 1.00 & 1.00 & 1.00 & 1.00 & 1.00 & 1.00 & 1.00 & 1.00 & 1.00 \\
\hline Date Pethick & 0.01 & 0.00 & 1.00 & 1.00 & 1.00 & 1.00 & 1.00 & 1.00 & 1.00 & 1.00 & 1.00 \\
\hline $\begin{array}{c}\text { Date Second } \\
\text { Woods }\end{array}$ & 0.00 & 0.00 & 0.00 & 0.55 & 0.69 & 0.91 & 0.90 & 0.97 & 0.96 & 0.99 & 0.97 \\
\hline Date Getman & 0.00 & 0.00 & 0.45 & 0.00 & 0.59 & 0.80 & 0.83 & 0.93 & 0.92 & 0.97 & 0.94 \\
\hline Date Elwood & 0.00 & 0.00 & 0.31 & 0.41 & 0.00 & 0.79 & 0.80 & 0.92 & 0.91 & 0.95 & 0.92 \\
\hline $\begin{array}{l}\text { Date Smith- } \\
\text { Pagerie }\end{array}$ & 0.00 & 0.00 & 0.09 & 0.20 & 0.21 & 0.00 & 0.57 & 0.73 & 0.74 & 0.81 & 0.77 \\
\hline $\begin{array}{c}\text { Date } \\
\text { Otstungo }\end{array}$ & 0.00 & 0.00 & 0.10 & 0.17 & 0.20 & 0.43 & 0.00 & 0.64 & 0.68 & 0.75 & 0.72 \\
\hline Date Klock & 0.00 & 0.00 & 0.03 & 0.07 & 0.08 & 0.27 & 0.36 & 0.00 & 0.68 & 0.75 & 0.72 \\
\hline $\begin{array}{c}\text { Date } \\
\text { Cayadutta }\end{array}$ & 0.00 & 0.00 & 0.04 & 0.08 & 0.09 & 0.26 & 0.32 & 0.45 & 0.00 & 0.52 & 0.55 \\
\hline Date Garoga & 0.00 & 0.00 & 0.01 & 0.03 & 0.05 & 0.19 & 0.25 & 0.39 & 0.48 & 0.00 & 0.55 \\
\hline $\begin{array}{c}\text { Date } \\
\text { Wormuth }\end{array}$ & 0.00 & 0.00 & 0.03 & 0.06 & 0.08 & 0.23 & 0.28 & 0.40 & 0.45 & 0.45 & 0.00 \\
\hline
\end{tabular}

Figure 6 A. Order probabilities between the site Phase Date estimates from a rerun of the Manning and Hart (2019) model 2 with the site Phase duration constraints changed to $\operatorname{LnN}(\ln (30), \ln (3))$ (see text). B. Order probabilities from the $\mathrm{U}(0,120)$ model run as shown in Manning and Hart (2019: Table 4). Probabilities for $t_{1}<t_{2}$, that is $t_{1}$ is older than $t_{2}$, are shown for each comparison. Values $>0.5$ are shaded red and in bold.

human cutting and use (so bark or waney edge is present or close), then this date gives a specific date range for use within a site Phase. For the Iroquoian site types discussed in this paper, we further know that the site Phases are not very long. For example, we adopted the Interval constraint of $\operatorname{LnN}(\ln (20), \ln (2))$ above for the period of time between the start Boundary and the End Boundary. Paired with the more specific date within the site Phase from the last ring of the wiggle-match, these two constraints can help better define the date of a site Phase. We employ an Interval query within the Phase as above.

Two examples for a hypothetical site dating AD 1480-1510 are shown in Figure 4. Charcoal A is a 30 tree-ring sample (and we can assume with bark or waney edge; these are found relatively regularly on what we assume likely to be a small roundwood sample). It is assumed in one case that this wood was used in the first year of the site Phase (so the building of the new village), and 
A

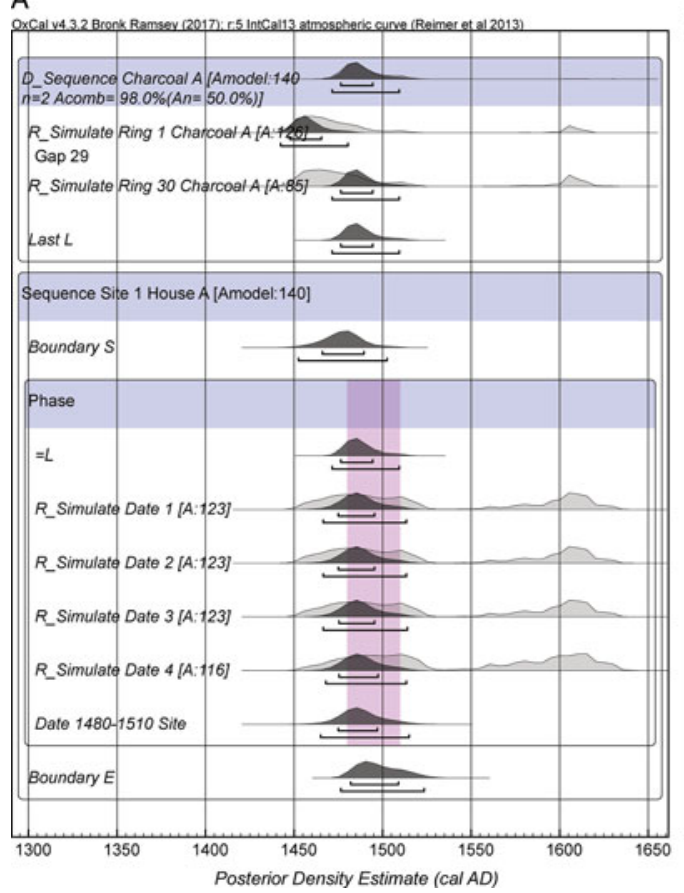

B

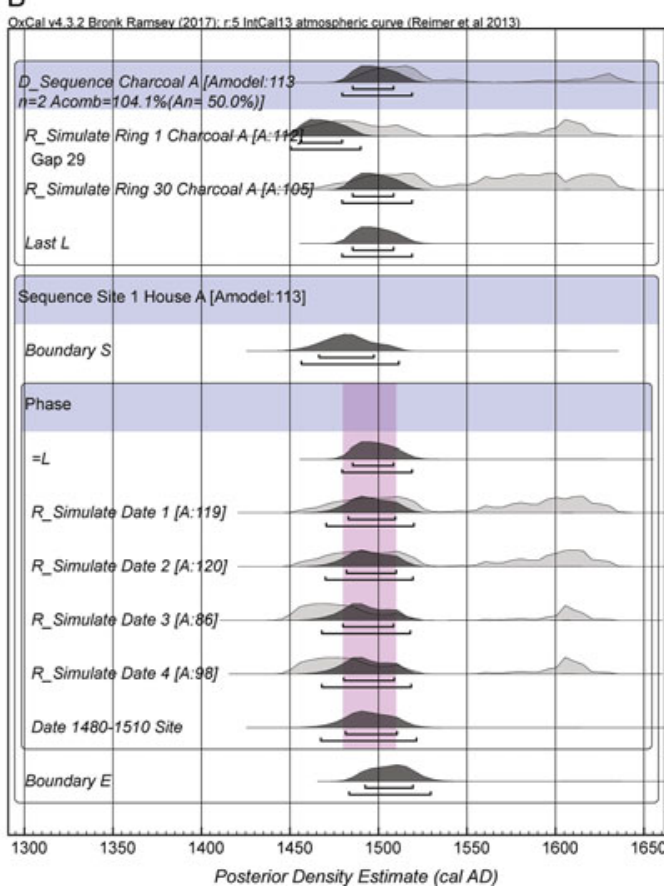

Figure 7 A. Example run of a model where a 30-yr charcoal sample comes from year 1 of a site Phase (e.g. construction). B. Example run where a $30-\mathrm{yr}$ charcoal comes from year 15 of the site Phase (so renewal, expansion, etc.). Time constraint is a uniform prior of $0-50 \mathrm{yr}, \mathrm{U}(0,50)$ applied with an Interval query between Boundary S to Boundary E (see text). Site Phase dates AD 1480-1510; light magenta bar indicates the site Phase date range. $68.2 \%$ and $95.4 \%$ hpd ranges are indicated. Compare with Figure 4.

in the second case it is assumed to date to year 15 of the village and to renewal or expansion in about the middle of the site's life-cycle. The outermost ring, ring 30, is placed in calendar terms by a two-date wiggle-match with a gap of $29 \mathrm{yr}$ from ring 1, and must lie within the site Phase, and the site Phase is constrained by the prior. The Figure 4 example employs the prior $\operatorname{LnN}(\ln (20), \ln 2))$. Figure 7 repeats the exercise but with a uniform prior of $0-50 \mathrm{yr}$ for comparison. The results are very similar. Another pair of examples for a hypothetical site mid-plateau, AD 1540-1570, are shown in Figure 8 (also assumed to be year 1 and year 15 of this site). In each instance, the modeled dates for the site Phase are by no means perfect, but they offer relatively good correspondence with the real site age and, in particular, much better estimates than the dates would in the absence of the TPQ and duration constraints. Figure 8A might, "by eye," seem the worst case illustrated, but even there the Date estimate for the site Phase yields $1520-1565$ (59.7\%) and $1625-1635(8.5 \%)$ at $68.2 \%$ hpd and $1510-1595(77.9 \%)$ and $1615-1644(17.5 \%)$ at $95.4 \%$ hpd. The correct date range (1540-1570) is fully within the most likely portion of the $95.4 \%$ range, and half the site range is within the most likely $68.2 \%$ range, and hence the Date estimate is broadly an accurate indicator, and so useful. To illustrate this point, Figure 9 shows Date estimates for a site Phase dating $1540-1570$ with just four random ${ }^{14} \mathrm{C}$ dates on short-lived samples (and no other constraint) from 10 example model runs. Compare these relatively widely dated estimates versus the (more constrained, if still imperfect) modeled results in Figure 8, which offer much greater resolution and a proximate association with the correct calendar period. 
A

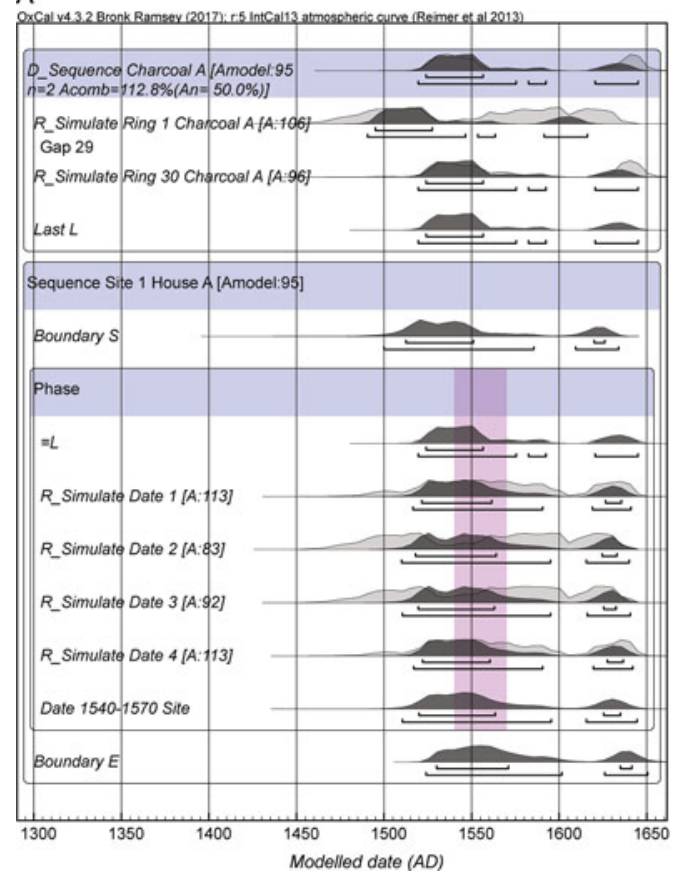

B

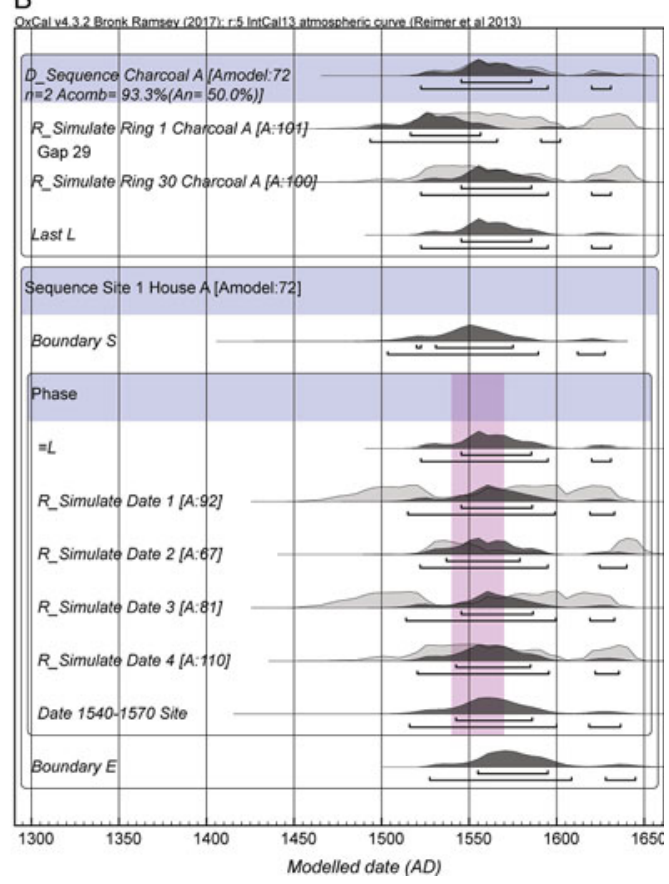

Figure 8 A. Example run of a model where a 30-yr charcoal sample comes from year 1 of a site Phase (e.g. construction). B. Example run where a 30-yr charcoal comes from year 15 of the site Phase (so renewal, expansion, etc.). Time constraint prior is $\operatorname{LnN}(\ln (20), \ln (2))$ applied with an Interval query between Boundary $S$ to Boundary E (see text). Site Phase dates AD 1540-1570; light magenta bar indicates the site Phase date range. $68.2 \%$ and $95.4 \%$ hpd ranges are indicated.

It is important to note that all runs of such simulations are different. We show example runs with both satisfactory OxCal $\mathrm{A}_{\text {model }}$ and $\mathrm{A}_{\text {overall }}$ values (and not just highest values from a set of runs) and with Convergence values $\geq 95$ (we highlight this last point). Depending on the selection of the R Simulate functions in each model run, an endless variety of possible options result. We show some typical examples. Needless to say, the scale of possible ambiguity can vary, but is improved versus the situation with no additional constraints (e.g. compare Figure 9 with Figure 8).

The conclusion drawn from this case is that use of even very short (e.g. 25-30+ yr) 2-date wiggle-match samples have the potential to substantially improve chronological resolution for the AD 1480-1630 Northeast (needless to say: longer wiggle-matches will usually be more secure and better resolved: e.g. Galimberti et al. 2004). An exception, without another constraint, is the very early 17 th century, unless the wiggle-match catches the reversal in ${ }^{14} \mathrm{C}$ values before $\sim 1605$, allowing distinction from the earlier 16 th century period. As highlighted in Bayliss et al. (2017), such short wiggle-matches may not always be entirely accurate. However, in the context of setting site Phase constraints, they will in nearly all cases provide useful information (see also Hogg et al. 2017), and the modeled outcomes are substantially more resolved and relatively accurate (meaning they nearly always include some part of the correct age range within the modeled Date estimate for a site Phase). The upcoming move to a robust single-year calibration dataset for the second millennium with IntCal20 (Reimer et al. 2020) will also improve accuracy and precision 


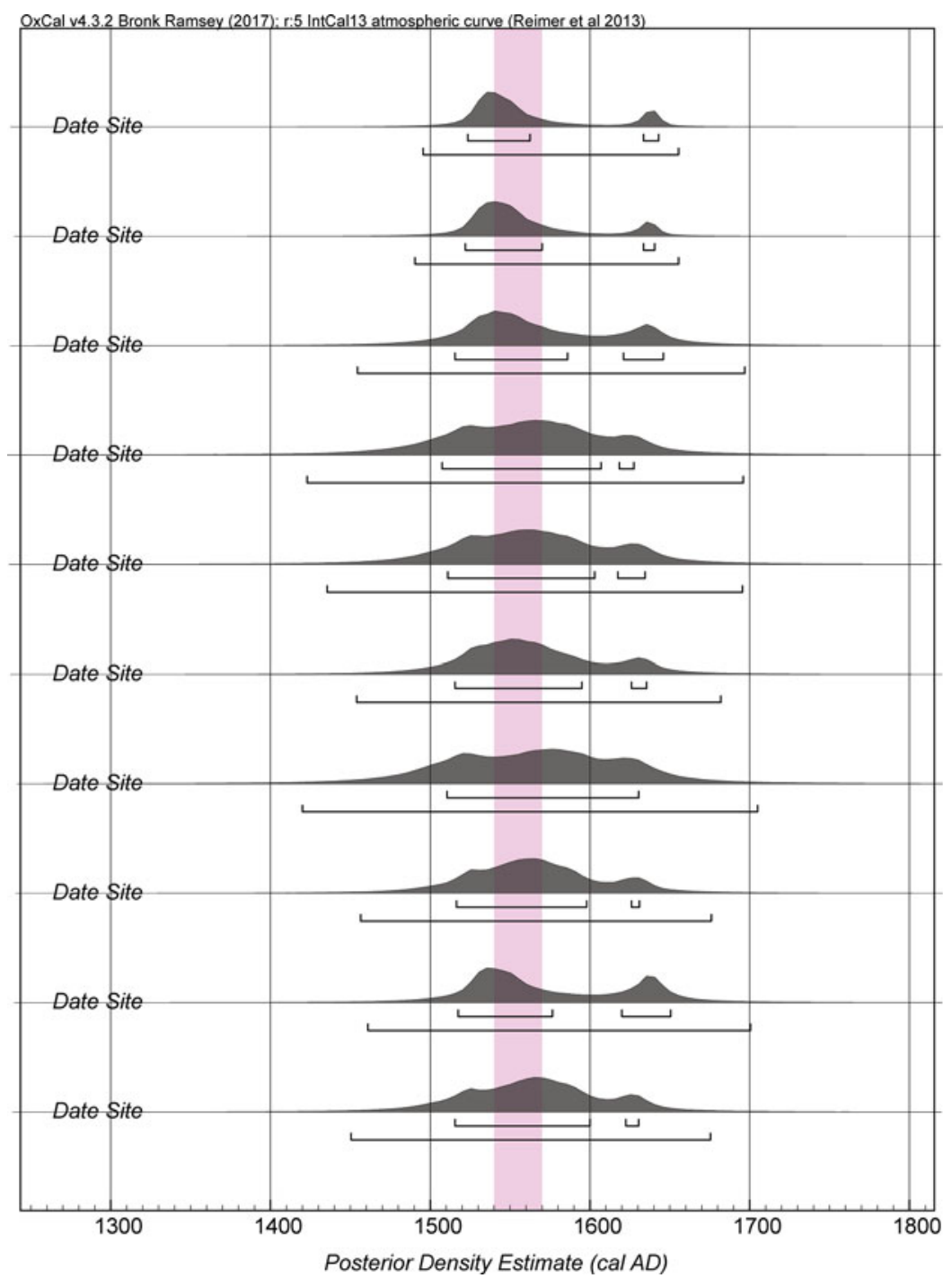

Figure 9 Date estimates for 10 runs of a site Phase with four random ${ }^{14} \mathrm{C}$ dates on shortlived samples. Site dates AD 1540-1570. No other constraints are applied. Compare with the modeled results in Figure 8 showing two examples of a site Phase dating 1540-1570 also with four random ${ }^{14} \mathrm{C}$ dates on short-lived samples but with a charcoal wiggle-match and a duration constraint applied.

(and will likely help alleviate some previous small inaccuracies, such as those observed in Bayliss et al. 2017). This approach thus offers a positive step forward versus ambiguity on a century-plus scale.

In turn, these potentials highlight the corollary: the need to acquire suitable wood-charcoal samples. It is important to affirm this need and the potential relevance and value of such wood-charcoal samples for archaeological chronologies, in addition to those samples on short-lived sample material which have become the standard focus of most archaeological 
${ }^{14} \mathrm{C}$ dating in recent years. Dates on (securely associated) short-lived samples of course have the potential to inform directly on the context of interest (Waterbolk 1970). Random charcoal with its in-built age may well be too old (Schiffer 1986; Ashmore 1999), although random sets of charcoal samples can nonetheless typically be assumed to offer information for the likely period of use with appropriate modeling (Bronk Ramsey 2009a; Dee and Bronk Ramsey 2014). But our point is that wood-charcoal (and its in-built age) securely associated with an archaeological context can act as a key dating constraint, and very particularly when the outermost ring (bark, waney edge) is present, and so should also be a focus of archaeological attention.

Up to now, the accessibility of suitable intact multi-tree-ring wood or wood-charcoal samples for detailed ${ }^{14} \mathrm{C}$ wiggle-matching is a fortunate, but uncommon, circumstance for many Iroquoian sites. However, at the same time, it must be observed that investigators have not until now been focused on trying to identify and preserve such samples (contrast archaeologists in the American southwest). It is to be hoped that the demonstrated utility of such samples, even ones with only $\sim 30$ or $\sim 50$ tree-rings (more is of course better) in the examples above, and in studies like Manning et al. (2018, 2019), will encourage those working in all pre-modern contexts to focus more closely on identifying and trying to recover potential wiggle-match samples. In northeastern North America longhouse timbers range from the relatively slender (juvenile tree stems or branches), likely lacking substantial ring counts, to larger central posts. For the latter, the diameters recorded would suggest suitable multi-decade to centennial ring counts potentially suitable for dendrochronology, and certainly radiocarbon wiggle-matching, if it is possible to successfully recover samples (see e.g. discussions, and data, in Wright 1974, 1995; Kapches 1993, 1994; Creese 2016). It is appreciated that recovery of preserved wood (as wood or charcoal) is sometimes a challenge in the Northeast. However, equally, there is the need for a prior focus on trying to identify such potential samples, and planning to best recover them, and their ring sequences, as central to excavation strategy. It is worth highlighting that a cross-section of such a timber need not be preserved perfectly as one solid section, but merely be securely reconstruct-able, even if recovered (carefully and fully documented in situ and subsequently) in pieces, to still potentially permit useful dendrochronology and wiggle-matching (compare e.g. Barfield et al. 2010). Even the relevance of one poorly preserved post fragment from the Warminster site should redirect attention to all and any wood-charcoal samples with multi-decade plus ring counts that can be securely associated with such site contexts (from houses, palisades, etc.). Note: no chemical consolidant, or preservative, should be employed on such samples-ever-if radiocarbon dating is even possibly anticipated in the future.

If such a wood-charcoal sample is found, the first aim is to document the sample in siturecording a later potential jigsaw of pieces as they were correctly assembled. Then the second aim is to keep the sample intact and with the segments in their original spatial association, while being especially mindful of retaining and protecting the outer surface (latest rings and best TPQ or potential felling date if bark or waney edge or sapwood are present). With care, wrap the sample securely in gauze bandage, and then tape around this to create a cocoon with the sample inside, before placing-with label with ID, locus and context information-in a box or protective container packed, with filling, so the sample(s) does not move around inside. Keep out of the sun, preferably in a cool location. A long ring count could permit dendrochronology. Even a few decades or more could enable useful radiocarbon wiggle-match dating which could offer key dating potential, as exploited in a range of other areas and periods (e.g. Bayliss and Tyers 2004; Galimberti et al. 2004; 
Barfield et al. 2010; Quarta et al. 2010; Manning et al. 2016; Hogg et al. 2017; Turkon et al. 2018).

What types of samples might be anticipated at Iroquoian archaeological sites in northeastern North America? Juvenile timber or branches are often employed for several elements in longhouses (Wright 1995). This limits likely ring counts but could still easily provide sufficient for a 25-30+ yr model use (as in the models in Figures 4, 7, and 8). Further, since juvenile trees growing under the canopy—of the types Wright (1995: 17-19) suggests were employed for various elements in longhouses-have suppressed growth and hence narrow rings, even small diameter wood/branches can in fact include several decades of growth. Such material may often yield relatively small diameter roundwood still with bark/ waney edge present. The main vertical posts in longhouses, however, could include older, mature, trees. Wright (1995: 17) regards Thuja occidentalis L., eastern white cedar, as the likely preferred choice where available-since it "is exceptionally rot-resistant in soil" (Warrick 1988; Wright 1995: 18; see Bouslimi et al. 2013: 4735-4736)-and this species is widespread in the region and long-lived (Johnston 1990). If we use this species as the example, Thuja occidentalis L. typically begins with a period of suppressed growth, before a release, followed by notably fairly even on-going growth (Hofmeyer et al. 2010). Based on one study, trees typically reached smaller "post" diameter $(\sim 12.7 \mathrm{~cm}$ diameter $)$ between $28-171 \mathrm{yr}$ of age, mean $96 \mathrm{yr}$, and large post/saw-timber diameter $(22.9 \mathrm{~cm})$ between 54 to $238 \mathrm{yr}$ of age, mean $\sim 140 \mathrm{yr}$ (Hofmeyer et al. 2010). Thus, if recovered, there is clearly considerable dendrochronological and/or wiggle-match potential.

\section{Duration Constraints on a Plateau}

The final modeling circumstance considered is the potential effectiveness of a duration constraint in isolation for, even slightly, better defining radiocarbon dating on a plateau. We compare Order resolution using four sets of example site Phases employing data drawn from IntCal13: Figure 10. If the Order analysis finds the correct site temporal order with probability $>50 \%$, then all the comparison cells in the grids above the orange diagonal line should be gray. Gray cells below the orange line indicate an incorrect Order finding. For the approximately 30-yr site Phase duration cases (Examples 1 and 2) the correct order is indicated in $80-93 \%$ of instances and the two uniform probability prior constraint instances, (ii) and (iii), (slightly) increase the correct probabilities versus the no constraint instance (i). The $\operatorname{LnN}(\ln (20), \ln (2))$ and $\mathrm{U}(15,7.5)$ constraints, (iv) and (v), actually achieve a slightly worse result than the no constraint instance in 2 of 4 cases. In all but one instance, Example 2 (v), the final site Phase period (f) of either 1598-1627 or 1613-1643 is mis-ordered. In Example 2 the penultimate site Phase period (e) of 1583-1612 is also misordered. The common issue is when the site range includes the period from about 15951620 (compare Figure 5). For the approximately 40-yr site Phase duration cases (Examples 3 and 4) the correct order is indicated in 90-100\% of cases except Example 4 (v) which is only $80 \%$ correct. The use of a site Phase duration constraint usually achieves a (slightly) better probability indication than the no constraint instances. The slightly longer site Phase appears to increase the prospects of a correct order indication. The site Phase that includes the entire 1595-1620 range is problematic when a shorter/tighter constraint is used (Example 4 (iv) and (v)).

Overall, these examples suggest that for the period not including around 1590-1620 especially, use of an Order analysis can potentially yield accurate indications, and use of various 

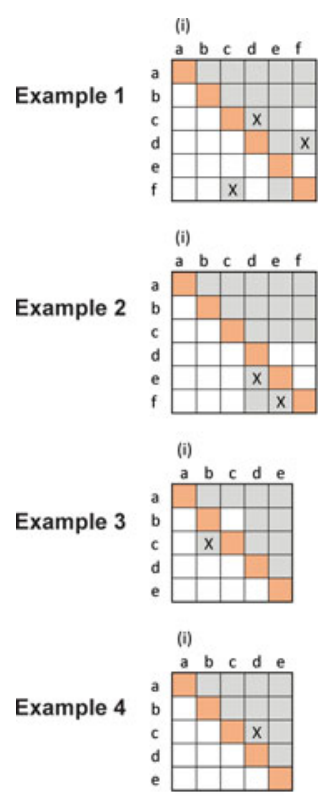

Example 1: a 1448-1477, b. 1478-1507, Example 3: a. 1448-1487, b. 1488-1527, c. 1528-1567, d. 1568-1607, e. 1608-1647 Example 4: a. $1463-1502$, b. $1503-1542$, c. $1543-1582$, d. 1583-1622, e. $1623-1662$

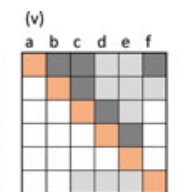

(v)

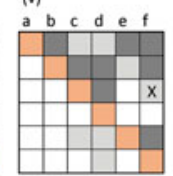

(v)

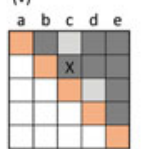

(v)

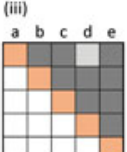

(iv)
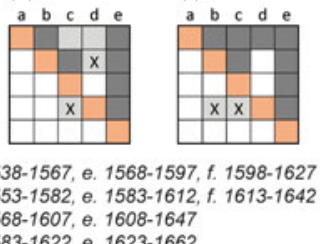

$\square<50 \%$ probability

$\square>50 \%$ probability

$>50 \%$ probability and greater probability than (i) for example

$>50 \%$ but $<55 \%$ probability

site Phase Date compared to itself

$$
\begin{aligned}
& \text { (i) No Interval Constraint } \\
& \text { (ii) } \mathrm{U}(0,120) \text { Interval Constraint } \\
& \text { (iii) } \mathrm{U}(0,80) \text { Interval Constraint* } \\
& \text { (iv) } \mathrm{LnN}(\ln (20) \text {, In(2)) Interval } \\
& \mathrm{Constraint} \\
& \text { (v) } \mathrm{N}(15,7.5) \text { (Examples } 1 \& 2) \\
& \text { and } \mathrm{N}(20,10) \text { (Examples } 3 \& 4) \\
& \text { Interval Constraint } \\
& \text { *U(0,100) for Example } 4 \text { (iii) } \\
& \text { where } \mathrm{U}(0,80) \text { and } \mathrm{U}(0,90) \\
& \text { usually do not give satisfactory } \\
& \text { Convergence values }
\end{aligned}
$$

Figure 10 Schematic representation of the four example Order analyses using groups of values from IntCal13 for (Examples 1\&2) six 30-yr site Phases and (Examples 3\&4) five 40-yr site Phases, and applying (i) no Interval constraint, (ii) a $\mathrm{U}(0,120)$ Interval constraint, (iii) a $\mathrm{U}(0,80)$ Interval constraint (except for Example 4 (iii) where it is a $U(0,100)$ Interval constraint because constraints of $U(0,80)$ or $U(0,90)$ usually failed to achieve satisfactory Convergence values $\geq 95$ ), (iv) a $\operatorname{LnN}(\ln (20), \ln (2))$ Interval constraint and (v) a $N(15,7.5)$ Interval constraint for Examples $1 \& 2$ and a $\mathrm{U}(20,10)$ Interval constraint for Examples $3 \& 4$, as described in the text. The correct order would see all the cells above the orange lines shaded gray.

case-appropriate site Phase duration constraints can slightly improve such resolution. In turn, these order indications_-noting caveats below_can be used to place the set of relevant site Phases into a proposed ordered series for a Sequence analysis which enables much greater chronological resolution (e.g. Buck et al. 1992; Bronk Ramsey 1995: 426-428). It must be noted, however, that probabilities are often less than decisive, and even with the Interval constraints applied they only rise slightly (see also Manning and Hart 2019: Appendix S1). For example, the comparisons with an " $\mathrm{X}$ " in Figure 10 indicate where the probability is $>50 \%$ but less than $55 \%$. This includes almost $10 \%$ of the correct order indications. It also includes $47 \%$ of the incorrect order findings in Figure 10, suggesting that the incorrect order results are only marginal in almost half such cases. The situation highlights that such Order findings are many times best seen as indicative. The addition, where possible, of extra constraints, such as a wiggle-match on a wood-charcoal sample (see above), is thus desirable.

\section{CONCLUSIONS}

Dating across the period of a plateau in the ${ }^{14} \mathrm{C}$ calibration curve inherently introduces challenges. However, allied with the ability to achieve much more precise ${ }^{14} \mathrm{C}$ dates on small (e.g. annual plant matter, or single or few tree-rings) samples using modern AMS ${ }^{14} \mathrm{C}$ 
dating, Bayesian approaches provide for a range of solutions. As shown in much work from the past three decades, where a known sequence is available, whether from a tree-ring series, stratigraphy, or historical information, good to at least reasonable resolution can be achieved (classic Sequence analysis). Cases lacking stratigraphic (or other) informed sequences remain more difficult. We considered in hypothetical terms the AD 1480-1630 reversal/plateau and the case of the relatively short duration Late Woodland village sites of northeastern North America. Here, despite the absence of stratigraphic sequences, we illustrated that use of even short tree-ring sequences from wood-charcoal samples paired with conservative ethnographically appropriate duration constraints could provide additional constraints to afford much greater chronological resolution. In addition, plausible culturally appropriate duration constraints by themselves can sometimes usefully assist temporal resolution. Where possible, the addition of a wood-charcoal wiggle-match enhances such resolution, which can in turn then be employed for a Sequence analysis. Contexts which date around the late part of the plateau on the ${ }^{14} \mathrm{C}$ calibration curve are especially problematic for duration constraint resolution. Here additional constraining information is necessary to achieve resolution - for example through inclusion of a wigglematch from a wood charcoal sample. Our overall conclusion is to highlight the potential value of even short wiggle-matches on wood charcoal samples with as few as $\sim 25-30+$ tree-rings. Such material forms a category of evidence which has been under-exploited in work to now. There is considerable potential to resolve and refine archaeological chronology across plateau periods using such samples (and more so when the finer structure of IntCal20 becomes available), in particular, when paired with an additional set of data and a second constraint.

\section{ACKNOWLEDGMENTS}

We thank the organizers of the Radiocarbon \& Archaeology Symposium at the University of Georgia. We thank the anonymous reviewers for their very useful and constructive comments and suggestions. This work was conducted in the context of the Dating Iroquoia project, and we gratefully acknowledge support from the National Science Foundation, award BCS 1727802 .

\section{SUPPLEMENTARY MATERIAL}

To view supplementary material for this article, please visit https://doi.org/10.1017/RDC. 2020.51

\section{REFERENCES}

Ashmore PJ. 1999. Radiocarbon dating: avoiding errors by avoiding mixed samples. Antiquity 73 : 124-130.

Barfield LH, Manning SW, Valzolgher E, Higham TFG. 2010. A wiggle-matched date for the Copper Age cemetery at Manerba del Garda, Northern Italy. Radiocarbon 52(3):984-1001.

Bayliss A, Marshall P, Tyers C, Bronk Ramsey C, Cook G, Freeman SPHT, Griffiths S. 2017. Informing conservation: Towards ${ }^{14} \mathrm{C}$ wiggle-matching of short tree-ring sequences from medieval buildings in England. Radiocarbon 59(3):985-1007.

Bayliss A, Tyers I. 2004. Interpreting radiocarbon dates using evidence from tree rings. Radiocarbon 46(2):957-964.

Biggar HP, editor. 1922-1936. The works of Samuel de Champlain. Six volumes. Translated by Langton HH, Ganong WF. Toronto: Champlain Society. Reprinted in 1971. Toronto: University of Toronto Press. 
Birch J. 2015. Current research on the historical development of northern Iroquoian societies. Journal of Archaeological Research 23:263-323.

Birch JA, Williamson RF. 2013. The Mantle site. An archaeological history of an ancestral Wendat community. Lanham: AltaMira.

Bouslimi B, Koubaa A, Bergeron Y. 2013. Variation of brown rot decay in eastern white cedar (Thuja occidentalis L.). BioResources 8:4735-4755.

Bronk Ramsey C. 1995. Radiocarbon calibration and analysis of stratigraphy: The OxCal program. Radiocarbon 37(2):425-430.

Bronk Ramsey C. 2009a. Bayesian analysis of radiocarbon dates. Radiocarbon 51(1):337-360.

Bronk Ramsey C. 2009b. Dealing with outliers and offsets in radiocarbon dating. Radiocarbon 51(3): 1023-1045.

Bronk Ramsey C. 2017. Methods for summarizing radiocarbon datasets. Radiocarbon 59(6):18091833.

Bronk Ramsey C, van der Plicht J, Weninger B. 2001. "Wiggle matching" radiocarbon dates. Radiocarbon 43(2A):381-389.

Buck CE, Kenworthy JB, Litton CD, Smith AFM. 1991. Combining archaeological and radiocarbon information - a Bayesian-approach to calibration. Antiquity 65:808-821.

Buck CE, Litton CD, Smith AFM. 1992. Calibration of radiocarbon results pertaining to related archaeological events. Journal of Archaeological Science 19:497-512.

Bursey JA. 1993. Prehistoric Huronia: Relative chronology through ceramic seriation. Ontario Archaeology 55:3-34.

Creese JL. 2016. Prolonger la charpente: la maisonlongue iroquoienne en tant que système sociotechnique. In: Chapdelaine C, Burke A, Gernigon K, editors. L'archéologie des maisonnées - pour une approche comparative transatlantique, Actes du colloque international, 24 et 25 octobre 2014, Université de Montréal, Palethnologie 8:11-32. doi:10.4000/palethnologie/ 391.

Dee MW, Bronk Ramsey C. 2014. High-precision Bayesian modeling of samples susceptible to inbuilt age. Radiocarbon 56(1):83-94.

Fitzgerald WR. 1986. Is the Warminster site Champlain's Cahiagué? Ontario Archaeology 45:3-7.

Fitzgerald WR, Knight DH, Bain A. 1995. Untanglers of matters temporal and cultural: Glass beads and the early contact period Huron Ball site. Canadian Journal of Archaeology 19:117-138.

Fitzgerald WR, Turgeon L, Whitehead RH, Bradley JW. 1993. Late sixteenth-century Basque banded copper kettles. Historical Archaeology 27:44-57.

Galimberti M, Bronk Ramsey C, Manning SW. 2004. Wiggle-match dating of tree-ring sequences. Radiocarbon 46(2):917-924.
Hamilton, WD, Haselgrove C, Gosden C. 2015. The impact of Bayesian chronologies on the British Iron Age. World Archaeology 47:642-660.

Hofmeyer PV, Kenefic LS, Seymour RS. 2010. Historical stem development of northern whitecedar (Thuja occidentalis L.) in Maine. Northern Journal of Applied Forestry 27:92-96.

Hogg A, Gumbley W, Boswijk G, Petchey F, Southon J, Anderson A, Roa T, Donaldson L. 2017. The first accurate and precise calendar dating of New Zealand Māori Pā, using Otāhau Pā as a case study. Journal of Archaeological Science: Reports 12:124-133.

Jacobsson P, Hamilton WD, Cook G, Crone, A, Dunbar E, Kinch H, Naysmith P, Tripney B, $\mathrm{Xu}$ S. 2018. Refining the Hallstatt plateau: Short-term ${ }^{14} \mathrm{C}$ variability and small scale offsets in 50 consecutive tree-rings from south west Scotland dendro-dated to $410-460$ BC. Radiocarbon 60(1):219-237.

Johnston WF. 1990. Thuja occidentalis L.-Northern white-cedar. In: Burns RM, Honkala BH, technical coordinators. Silvics of North America. Vol. 1: Conifers. Agricultural Handbook 654. Washington, DC: Forest Service, United States Department of Agriculture. p. 580-589.

Jope EM. 1986. High-precision radiocarbon dating. The Antiquaries Journal 66:358-360.

Kapches M. 1993. The Ontario Iroquoian longhouse ca. 1350 to ca. 1640: A study in vernacular architecture. In: Beck J, Keefer A, editors. Vernacular architecture in Ontario. Toronto: Architectural Conservancy of Ontario. p. 3-15.

Kapches M. 1994. The Iroquoian longhouse: architectural and cultural identity. In: Locock M, editor. Meaningful architecture: social interpretation of buildings. Brookfield, VT: Ashgate Publishing. p. 253-270.

MacNeish RS. 1952. Iroquois pottery types: a technique for the study of Iroquois prehistory. Ottawa: National Museum of Canada.

Manning SW, Birch J, Conger MA, Dee MW, Griggs C, Hadden C. 2019. Contact-Era chronology building in Iroquoia: Age estimates for Arendarhonon sites and implications for identifying Champlian's Cahiagué. American Antiquity 84:684-707.

Manning SW, Birch J, Conger MA, Dee MW, Griggs C, Hadden CS, Hogg AG, Bronk Ramsey C, Sanft S, Steier P, Wild EM. 2018. Radiocarbon re-dating of contact-era Iroquoian history in northeastern North America. Science Advances 4: eaav0280.

Manning SW, Hart JP. 2019. Radiocarbon, Bayesian chronological modeling and early European metal circulation in the sixteenth-century AD Mohawk River Valley, USA. PLoS ONE 14(12):e0226334

Manning SW, Griggs CB, Lorentzen B, Barjamovic G, Bronk Ramsey C, Kromer B, Wild EM. 2016. 
Integrated tree-ring-radiocarbon high-resolution timeframe to resolve earlier second millennium BCE Mesopotamian chronology. PLoS ONE 11(7):e0157144.

Park J, Southon J, Fahrni S, Creasman PP, Mewaldt R. 2017. Relationship between solar activity and $\Delta^{14} \mathrm{C}$ peaks in AD 775, AD 994, and $660 \mathrm{BC}$. Radiocarbon 59:1147-1156.

Pearl JK, Anchukaitis KJ, Donnelly JP, Pearson C, Pederson N, Gaylord MCL, McNichol AP, Cook ER, Zimmermann GL. 2020. A late Holocene subfossil Atlantic white cedar treering chronology from the northeastern United States. Quaternary Science Reviews 228:106104.

Pendergast JF. 1993. Some comments on calibrated radiocarbon dates for St. Lawrence Iroquoian sites. Northeast Anthropology 46:1-31.

Quarta G, Pezzo MI, Marconi S, Tecchiati U, Elia MD, Calcagnile L. 2010. Wiggle-match dating of wooden samples from Iron Age sites in Northern Italy. Radiocarbon 52(2-3):915-923.

Reimer PJ, Bard E, Bayliss A, Beck JW, Blackwell P, Bronk Ramsey C, Buck CE, Cheng H, Edwards RL, Friedrich M, Grootes PM, Guilderson TP, Haflidason H, Hajdas I, Hatté C, Heaton TJ, Hoffmann DL, Hogg AG, Hughen KA, Kaiser KF, Kromer B, Manning SW, Niu M, Reimer RW, Richards DA, Scott EM, Southon JR, Staff RA, Turney CSM, van der Plicht J. 2013. IntCal13 and Marine13 radiocarbon age calibration curves $0-50,000$ years cal BP. Radiocarbon 55(4):1869-1887.

Reimer PJ, Austin WEN, Bard E, Bayliss A, Blackwell P, Bronk Ramsey C, Butzin M, Edwards L, Friedrich M, Grootes PM, et al. 2020. The IntCal20 Northern Hemisphere radiocarbon age calibration curve $(0-55$ cal kBP). Radiocarbon 62. In press.

Schiffer MB. 1986. Radiocarbon dating and the "old wood" problem: the case of the Hohokam chronology. Journal of Archaeological Science 13:13-30.
Snow DR. 1995. Mohawk Valley archaeology: The sites. Occasional Papers in Anthropology 23. University Park: Matson Museum of Anthropology, The Pennsylvania State University.

Sykes CM. 1980. Swidden horticulture and Iroquoian settlement. Archaeology of Eastern North America 8:45-52.

Taylor RE, Southon J. 2013. Reviewing the mid-first millennium $\mathrm{BC}{ }^{14} \mathrm{C}$ "warp" using ${ }^{14} \mathrm{C} /$ bristlecone pine data. Nuclear Instruments and Methods in Physics Research B 294:440-443.

Taylor RE, Stuiver M, Reimer PJ. 1996. Development and extension of the calibration of the radiocarbon time scale: Archaeological applications. Quaternary Science Reviews 15:655-668.

Thwaites RG. 1896-1901. The Jesuit relations and allied documents. 73 volumes. Cleveland $(\mathrm{OH})$ : The Burrows Brothers Company.

Timmins PA. 1997. The Calvert site: An interpretative framework for the early Iroquoian village. Mercury Series Archaeological Survey of Canada, Paper 156. Gatineau: National Museum of Civilization.

Turkon P, Manning SW, Griggs C, Santos Ramírez M, Nelson B, Torreblanca Padilla C, Wild E. 2018. Applications of dendrochronology in northwestern Mexico. Latin American Antiquity 29:102-121.

Warrick GA. 1988. Estimating Ontario Iroquoian village duration. Man in the Northeast 36:21-60.

Waterbolk HT. 1970. Working with radiocarbon dates. Proceedings of the Prehistoric Society 37: $15-33$.

Wright JV. 1974. The Nodwell site. Ottawa: National Museums of Canada.

Wright JV. 1995. Three dimensional reconstructions of Iroquoian longhouses: A comment. Archaeology of Eastern North America 23:9-21.

Wrong GM, editor. 1939. Sagard's long journey to the country of the Hurons [1632]. Toronto: Champlain Society. 